\title{
OS CONTEÚdOS DAS VISÕES DA AYAHUASCA*
}

Benny Shanon

A ayahuasca é uma infusão vegetal psicoativa da Amazônia. Tipicamente, provoca poderosas visões, assim como alucinações em todas as demais modalidades de percepção. Essas experiências geralmente se associam a insights pessoais, ideações intelectivas, reações afetivas e experiências espirituais e místicas profundas. Também se observam alterações dos parâmetros básicos da experiência — identidade pessoal, conexão com o mundo exterior, temporalidade e os sentimentos de significação e de noese. No passado, a ayahuasca era um dos pilares centrais de várias culturas tribais da Amazônia. Hoje, a infusão ainda é instrumento corriqueiro dos curandeiros em toda a região. Além disso, no decorrer do século XX, constituíram-se no Brasil vários grupos religiosos sincréticos nos quais as tradições indígenas relativas à ayahuasca se combinam com elementos culturais não-indígenas - cristãos ou outros. Dentre esses grupos, os mais importantes são a Igreja do Santo Daime, a União do Vegetal (abreviadamente, UdV) e a Barquinha. Em todos, a ayahuasca funciona como um sacramento.

Dada a orientação psicológica deste artigo, não se fará aqui uma revisão extensa da literatura antropológica sobre a ayahuasca. Para informações pertinentes a respeito do uso indígena da mesma, o leitor deverá consultar Reichel-Dolmatoff $(1971 ; 1975 ; 1978 a ; 1996 ; 1997)$, Dobkin de Rios (1972; 1973), Furst (1976; 1990), Langdon (1979a; 1979b; 1992a), Luna (1986a), Luna e White (2000), Metzner (1999), bem como as contribuições em Harner (1973a), Labate e Araújo (2002) e o número especial de América Indígena (1986). Para informações gerais sobre os grupos sincréticos que utilizam a ayahuasca, ver Polari (1984; 1992), MacRae (1992), Centro de Memória e Documentação (1989), Brissac (1999), Groisman (1999) e Sena Araújo (1999). Trabalho singular é a obra em colaboração do antropólogo Luna e do xamã e pintor Pablo Amaringo (Luna e Amaringo 1993), que consiste em uma coleção de reproduções de pinturas nas 
quais são apresentadas visões da ayahuasca. Uma bibliografia sucinta da pesquisa científica sobre a ayahuasca encontra-se em Luna (1986b). Informações adicionais relativas aos aspectos botânicos e farmacológicos da ayahuasca são fornecidas em Chen e Chen (1939), Der Marderosian, Pinkley e Dobbins (1968), Holmstedt e Lindgren (1979), Schultes e Hofmann (1980), Schultes (1972; 1982; 1986), Schultes e Winkelman (1995), Ott (1993; 1994), bem como em Grob et alii (1996) e Callaway et alii (1999); informações sobre o DMT (o princípio ativo primário da ayahuasca) e seus efeitos encontram-se em Strassman (2001).

\section{O estudo cognitivo-psicológico da ayahuasca}

Praticamente toda a pesquisa científica sobre a ayahuasca está dividida em duas categorias: a das ciências naturais - botânica e etnobotânica, farmacologia, bioquímica e fisiologia do cérebro - e a das ciências sociais - notadamente a antropologia. Em minha opinião, nenhuma delas vai ao cerne da questão. Ambas as linhas de investigação consideram a ayahuasca, por assim dizer, do exterior. Evidentemente, a ayahuasca não seria conhecida por nós no Ocidente não fossem as aventuras e o arrojo de botânicos e antropólogos. Mas os efeitos especiais da ayahuasca uma vez descobertos nem por isso se tornam botânicos ou antropológicos; eles envolvem as experiências subjetivas das pessoas. Portanto, o ponto que sustento é que os verdadeiros problemas associados a essa infusão não têm a ver com o cérebro nem com a cultura, e sim com a mente humana.

Meu interesse profissional na experiência da ayahuasca baseia-se na avaliação de que a aliança das pesquisas sobre essa substância e dos estudos da mente é de mão dupla (meu argumento está mais extensamente exposto em Shanon 1997; 1998a; 2000; 2002a; 2002b; 2002c). Por um lado, a psicologia cognitiva apresenta uma perspectiva nova e muito apropriada às investigações sobre a ayahuasca. Esta, por sua vez, com os fenômenos ímpares que produz, abre novos panoramas para o estudo da mente em geral e da consciência humana em particular. Ademais, parece-me que a abordagem cognitivo-psicológica da ayahuasca pode lançar luz sobre fenômenos pertencentes a províncias de outras disciplinas, notadamente a filosofia e o estudo da cultura.

Guiado pelas convicções acima expostas, empreendi um amplo projeto de pesquisa, cujo objetivo é mapear sistematicamente os vários fenômenos que podem ser provocados pela ayahuasca e ordená-los. Nesse esforço, minha meta principal é, seguindo a orientação de Aldous Hux- 
ley (ver Huxley 1956), levantar a geografia das regiões recônditas da psique - os antípodas da mente, na terminologia desse autor -, ocultas em nosso estado ordinário e reveladas pela ayahuasca. Um relato mais extenso dessa pesquisa é apresentado em Shanon (2002c).

\section{As visões da ayahuasca}

Neste artigo, abordo a faceta mais conhecida da experiência da ayahuasca - a visual. As visões da ayahuasca são valorizadas em todos os contextos - tradicionais bem como modernos — nos quais a infusão é utilizada.

Cabe fazer uma distinção terminológica. Na literatura, emprega-se o termo comum "visões". Pessoalmente, prefiro fazer distinção entre os termos "visualização" e "visão". Emprego o primeiro para designar todo efeito visual provocado pela ayahuasca, ao passo que o segundo denota apenas as visualizações que apresentam certo grau de extensão temporal e conteúdo semântico. Para representações artísticas da ayahuasca, ver Luna e Amaringo (1993), já mencionado acima, e também os trabalhos de Alexandre Segregio, Ernesto Giovanni Boccara e Ceú, reproduzidos em Weiskopf (1995) e Shanon (2002b; 2002c), respectivamente.

Quando, na literatura antropológica, se coloca a questão sobre "o que se vê nas visões da ayahuasca?" (eu, aqui, diria visualizações), a discussão envolve, quase sem exceção, uma especificação dos elementos de conteúdo que aparecem nas visões. Uma afirmação típica seria algo similar a: "Vêem-se jaguares, ou cobras, ou pessoas conhecidas." Este artigo também se ocupa desses elementos de conteúdo, mas é importante considerar que a análise destes é apenas uma entre várias que se podem conduzir na investigação das visões. Antes de passar ao ponto enfocado neste trabalho, situarei a presente discussão em seu contexto mais amplo, e o farei em contraste com outras análises que podem (e devem) ser empreendidas.

O primeiro contraste é entre conteúdo e forma. As visualizações da ayahuasca podem aparecer em diferentes formas. Visualizações podem diferir quanto à intensidade da percepção, estabilidade, extensão temporal e também quanto ao impacto psicológico e/ou espiritual que vêm a ter nas pessoas. Por exemplo, algumas visões consistem em elementos de conteúdo isolados, outras apresentam cenários ricos e em outras, ainda, se desenrolam longas narrativas.

O segundo contraste é relativo à esfera do conteúdo. Distingo os níveis micro e macro de análise: o primeiro diz respeito aos elementos de 
conteúdo e o segundo, aos temas. Para esclarecer esse contraste, gostaria de recorrer a uma analogia do domínio da literatura. Qual o conteúdo das tragédias de Shakespeare? Para responder a esta pergunta, o estudioso pode submeter os textos das tragédias shakespearianas a uma análise estatística e contar os elementos que neles aparecem. Aqueles que provavelmente terão mais alta contagem são reis e rainhas, chefes militares, palácios, adagas etc. etc. Mas tais listas de itens não nos fornecem uma resposta para a seguinte questão: "As tragédias são sobre o quê?" Algumas categorias pertinentes a esta questão poderiam ser: "os efeitos destrutivos do poder e da cobiça" e "relações entre pais e filhos".

Acresce que as visualizações (ou, melhor, as visões) variam segundo a atitude dos bebedores ${ }^{1}$ diante delas. Mais especificamente, ver é apenas uma espécie de relação. Quando as visualizações são complexas e é alto o grau de envolvimento, os bebedores podem colocar-se ativamente em interação com suas visões e desempenhar toda sorte de atos associados a elas. Eles podem "passar para dentro" da cena da visão, percorrêla e/ou agir e interagir com objetos e criaturas que encontram. Quando bastante complexas, as visões também podem ser analisadas em termos de sua estrutura narrativa. Uma tipologia das espécies estruturais das visões da ayahuasca e dos vários padrões de interação que lhes são associados é apresentada em Shanon (2002b).

\section{Recorrências no conteúdo das visões da ayahuasca}

Da literatura antropológica sobre a ayahuasca emerge um padrão surpreendente, que é o da recorrência de certos elementos comuns às visões provocadas pela infusão. Assim, em uma revisão da literatura antropológica (menos recente), Harner (1973b) conclui que os itens mais comuns ${ }^{2}$ nas visões relatadas por indígenas são cobras, jaguares, demônios e deidades, cidades e paisagens. Também se encontram, segundo seu relato, visões relativas à solução de crimes, vôos da alma e experiências de clarividência. Observações similares são apresentadas em Der Marderosian et alii (1970), Naranjo (1973a), Furst (1990) e Grob (1999).

A pesquisa aqui relatada tem por propósito estabelecer empírica e sistematicamente a recorrência, nas visões de diferentes pessoas, de elementos de conteúdo. Isso se dá mediante a comparação de dados fornecidos por muitos grupos de informantes, com diversas histórias pessoais e ambientes socioculturais variados; os informantes também diferem quanto ao nível de experiência com a infusão. 
Embora a existência de traços comuns às visões tenha sido observada de modo informal por muitos usuários de ayahuasca, até hoje não foi realizada nenhuma investigação sistemática a esse respeito. Especificamente, os relatos encontrados na literatura antropológica estão geralmente baseados em entrevistas (por vezes extensas, como no caso de Reichel-Dolmatoff) realizadas com indivíduos isolados (alguns de longa experiência pessoal com a ayahuasca), mas não na interrogação sistemática de grupos. Meu estudo é o primeiro a tentar uma tal investigação sistemática. Resultados preliminares e parciais dessa investigação estão relatados em Shanon (1998b) e em Shanon (2002a); detalhes suplementares são apresentados em Shanon (2002c).

O presente projeto de pesquisa é pioneiro em diversos aspectos. $\mathrm{Pa}-$ ra começar, e principalmente, é a primeira investigação empírica de tipo cognitivo-psicológico realizada sobre a experiência da ayahuasca. $\mathrm{Na}$ verdade, com exceção do trabalho clínico conduzido por Naranjo trinta anos atrás (1973a; 1979; 1973b) e dos testes clínicos-psicológicos aplicados por Grob e colaboradores no quadro do Projeto Hoasca, de natureza médica (Grob et alii 1996; McKenna, Callaway e Grob 1998; Callaway et alii 1999), este é o único estudo psicológico sistemático da ayahuasca jamais realizado.

Este é também o mais amplo levantamento de dados sobre a fenomenologia da experiência da ayahuasca a ser realizado e relatado. Além disso, é o primeiro estudo sistemático, na literatura científica, baseado em um grande corpus de dados coletados em primeira mão. Muitos antropólogos que investigaram e escreveram sobre a ayahuasca só a ingeriram umas poucas vezes e não tiveram com ela mais que uma experiência rudimentar; alguns não tiveram nenhuma experiência direta (para mais comentários a esse respeito, ver Harner 1973c, especialmente página 16; Mabit 1988; Davis 1996 e Narby 1998) ${ }^{3}$.

Devem-se também sublinhar os aspectos quantitativos desta investigação. Eles dizem respeito à coleta de dados e também à análise destes. Curiosamente, a literatura antropológica não fornece mais que raras referências quanto ao tópico da informação quantitativa. Geralmente, os estudos antropológicos sobre a ayahuasca apresentam breves relatos das experiências de vários membros de determinado grupo étnico (ver, p. ex., Harner 1973b). Com grande freqüência, não há indicação do número de pessoas entrevistadas, nem qualquer especificação da distribuição quantitativa dos dados entre os informantes.

Os dados aqui apresentados também são especiais por sua heterogeneidade. Usualmente, quando um antropólogo estuda a ayahuasca, con- 
centra-se em determinada comunidade, o que é natural, pois o foco principal é na sociedade e na cultura. Por estar, ao contrário, interessado na dimensão psicológica, eu deliberadamente estudo a ayahuasca em diferentes contextos. Estes diferem quanto à natureza da comunidade em que a sessão foi realizada (p. ex., indígena ou não, religiosa ou não), quanto ao tipo de sessão (p. ex., rito religioso, sessão de cura, celebração ou sem nenhum ritual) e quanto ao local. Todas essas variações também se aplicam aos contextos em que eu mesmo experimentei a ayahuasca.

\section{Os dados}

As análises aqui apresentadas estão baseadas em vários conjuntos de dados, os quais incluem meus registros pessoais, informações obtidas de outras pessoas e dados extraídos da literatura. Ao todo, foram examinados doze conjuntos de dados relativos às visões da ayahuasca. Além disso, para fins comparativos, relatos de sonhos também são analisados. Seguem-se informações relativas aos diferentes conjuntos e aos procedimentos de coleta.

\section{Meus próprios dados}

Ao todo, participei ativamente de cerca de 140 sessões de ayahuasca, realizadas em diversos contextos. Como era necessário estabelecer alguma linha demarcatória, decidi incluir na presente análise quantitativa apenas as 67 sessões anteriores a 1996, quando comecei a analisar os dados. Portanto, os dados concernentes a essas sessões serão referidos como corpus central e identificados como conjunto no 1 .

O corpus central baseia-se em sessões com os seguintes contextos: os vários rituais da Igreja do Santo Daime (20 sessões), os encontros da União do Vegetal (11 sessões), a Barquinha (1 sessão), curas conduzidas por xamãs indígenas ou mestiços (18 sessões) e consumo privado - seja na companhia de pequeno número de pessoas (15 sessões), seja desacompanhado (5 sessões) ${ }^{4}$.

As sessões conduzidas nos contextos das seitas religiosas se deram em diferentes comunidades por todo o Brasil. Aquelas dirigidas por curandeiros tradicionais se deram em várias regiões da Amazônia peruana - nas cidades de Pucallpa, Iquitos, Puerto Maldonado e em aldeias próximas. Os curandeiros eram membros de diferentes grupos indígenas (es- 
pecificamente: Shipibo, Yagua, Cocama e Lamas) ou indivíduos de ascendência mista. Ingeri também ayahuasca com ayahuasqueros (i.e., xamãs que fazem uso da ayahuasca) da tribo Inga, no vale Sibundoy e junto ao rio Putumayo, na Colômbia meridional. As sessões privadas foram realizadas na companhia de pessoas às quais me refiro como "bebedores independentes".

\section{Dados coligidos de outras pessoas}

Minha segunda fonte de dados foram entrevistas em que indaguei sobre a experiência das pessoas com a ayahuasca. As entrevistas eram de dois tipos: estruturadas e não estruturadas. Eu mesmo realizei pessoalmente todas elas, separadamente e face a face com cada entrevistado, sem a presença de terceiros. Ao todo, entrevistei 178 pessoas (122 homens e 56 mulheres): 46 em entrevistas estruturadas, 128 em entrevistas não estruturadas e quatro de quem obtive o registro completo de todas as suas experiências com a ayahuasca. Dezesseis informantes eram indígenas ou mestiços, 106 residentes em regiões urbanas da América do Sul e 56 estrangeiros (ou seja, de fora da América do Sul).

As entrevistas estruturadas centraram-se em um questionário que abordava o conjunto da experiência dos informantes com a infusão, cujo objetivo era ter acesso a diferentes aspectos dessa experiência. Eram apresentados aos informantes diferentes categorias de conteúdo, e eralhes perguntado se já tinham visto elementos pertencentes àquelas categorias. Uma resposta afirmativa indicava que o item em questão havia sido visto pelo informante ao menos uma vez ao longo de toda a sua experiência com a ayahuasca ${ }^{5}$.

No que diz respeito à sua experiência, os informantes que participaram das entrevistas estruturadas pertencem a quatro grupos. O primeiro, o dos "bebedores independentes": 18 indivíduos que consumiam regularmente a ayahuasca mas que, à época das entrevistas, não pertenciam a nenhum grupo institucionalizado. Todos residiam no Brasil, a maioria no Rio de Janeiro. Para eles, a ayahuasca era o aspecto central de suas vidas e todos a consumiam regularmente na época da entrevista. Todos tinham no mínimo quatro anos de experiência com a bebida e já a haviam consumido pelo menos quarenta vezes (e, em vários casos, muito mais que isso). Devo esclarecer que a caracterização desses informantes como grupo refere-se apenas aos propósitos da minha pesquisa; a maioria das pessoas a ele pertencente não se conhece, e ele não constitui absoluta- 
mente um grupo em qualquer sentido social ou interpessoal. Cada entrevista teve ao menos uma hora de duração; algumas se estenderam por até seis horas.

O segundo e terceiro grupos de informantes submetidos a questionários estruturados eram membros da União do Vegetal (UdV) e do Santo Daime - com quatorze e sete pessoas, respectivamente. Todos tinham vasta experiência com a ayahuasca.

O quarto grupo é constituído de pessoas que não eram afiliadas a nenhum grupo institucionalizado, mas que, diferentemente dos bebedores independentes mencionados acima, tinham experiência limitada com a ayahuasca - entre dez e quarenta sessões. Esse grupo inclui dez pessoas, todas não-indígenas e residentes em centros urbanos. Entre elas estão as quatro que forneceram os relatos completos - registrados por escrito ou em diários pessoais - das sessões de que participaram. As outras seis foram entrevistadas a partir do questionário estruturado.

As entrevistas estruturadas geraram três conjuntos de dados, cada um fornecido por um grupo de informantes. O primeiro, conjunto no 4, é baseado em entrevistas com o grupo de bebedores independentes com ampla experiência com a ayahuasca; o segundo, conjunto no 5, é baseado em entrevistas com os bebedores independentes de experiência mais limitada; o terceiro, conjunto no 6, é baseado nas entrevistas com os membros do Santo Daime e da UdV. De agora em diante, os grupos e os conjuntos de dados a eles correspondentes serão respectivamente designados como independentes $I$, independentes II e afiliados; os membros do Santo Daime e da UdV foram agrupados em uma só rubrica, pois separadamente constituíam grupos muito pequenos.

Cabe um comentário sobre a exatidão dos dados coligidos por meio de entrevistas estruturadas. As respostas afirmativas às perguntas desse questionário não constituem indicadores nem da distribuição real dos conteúdos investigados nem das suas freqüências relativas. Elas também acabam resultando em valores numéricos relativamente altos. Ainda assim, os dados disponíveis têm, quanto a outros aspectos, uma virtude especial: por serem extraídos de um amplo repertório de experiências, eles são capazes de fornecer um bom quadro geral dos tipos de conteúdo encontrados nas visões da ayahuasca. De fato, os questionários refletem um considerável corpus total acumulado de experiências visionárias. Minha estimativa é a de que, ao todo, os dados aqui discutidos estão baseados em aproximadamente 2.500 sessões de ayahuasca.

Nas entrevistas não estruturadas, os informantes eram indagados sobre sessões específicas: sua primeira experiência com a bebida, a ex- 
periência mais notável que já tiveram e detalhes de alguma sessão em especial (geralmente, uma sessão da qual eu e o entrevistado havíamos acabado de participar). Entre os informantes, incluíam-se indígenas e não-indígenas, xamãs e mestres de cerimônia da ayahuasca, pessoas com longa experiência e também algumas que a estavam consumindo pela primeira vez; entre estas últimas, havia tanto sul-americanos quanto estrangeiros que nada conheciam da ayahuasca antes de consumi-la pela primeira vez. As entrevistas foram feitas em diferentes lugares no Brasil e no Peru e também fora da América do Sul.

Três conjuntos de dados foram gerados pelas entrevistas não estruturadas e eles correspondem aos três tipos de sessão ou experiência abordados nas perguntas: primeira, melhor e específica, respectivamente. Entre os informantes entrevistados sobre esses três tipos de sessão incluíamse indígenas americanos, residentes não-indígenas da América do Sul (doravante designados sul-americanos) e estrangeiros.

Os dados relativos à primeira sessão ou experiência dos entrevistados foram separados em dois grupos: o dos informantes não-indígenas (sul-americanos e estrangeiros) e o dos indígenas. Com relação à melhor experiência ou a sessões específicas, o número de informantes não exigia subdivisão segundo a identidade dos informantes. Ao todo, portanto, há quatro conjuntos de dados relativos a sessões ou experiências individuais: os conjuntos no 7 e no 8 para a primeira experiência (dos informantes nãoindígenas e indígenas, respectivamente), o conjunto o 9 para a melhor experiência e o conjunto ํo 10 para sessões específicas.

Dos 152 indivíduos entrevistados sobre sua experiência inicial, quinze eram indígenas e 136, não (destes, 81 sul-americanos residentes em cidades e 55 estrangeiros). Relatos das primeiras sessões são especialmente interessantes pois correspondem a um estágio em que as experiências dos informantes têm menos probabilidade de serem afetadas por expectativas, conhecimentos prévios, informações compartilhadas ou doutrinação pelo grupo.

Cinqüenta e um indivíduos foram entrevistados sobre suas "melhores" experiências. A razão de ser desse tipo de pergunta é dupla. Quantitativamente, em uma sessão intensa pode haver mais detalhes de conteúdo que em várias sessões menos intensas. Assim, focalizar as melhores sessões pode trazer maximização de informação. Qualitativamente, os conteúdos que aparecem nas sessões intensas podem ser mais ricos, extraordinários e ter maior impacto pessoal e/ou espiritual. Entre os 51 entrevistados para esse conjunto, dezesseis eram membros do primeiro grupo de bebedores independentes, sete do segundo grupo de bebedores 
independentes, quatorze do grupo dos afiliados, seis eram membros da UdV não incluídos no grupo de afiliados, dois xamãs indígenas, dois sulamericanos (não-indígenas) e quatro estrangeiros.

Sessões específicas foram investigadas sempre que havia oportunidade de perguntar às pessoas sobre suas experiências; em geral, isso se dava imediatamente após sessões de que eu mesmo havia participado. Vinte e duas pessoas foram entrevistadas dessa forma: oito sul-americanos, oito indígenas ameríndios e seis estrangeiros. Tomados em conjunto, os dados sobre as sessões específicas podem ser considerados como uma enquete baseada em amostragem aleatória, similar às que se fazem em ciências sociais quando se quer obter informação relativa a populações. Diferentemente dos dados coletados por intermédio do questionário estruturado, aqueles relativos a sessões específicas não se reportam a avaliações retrospectivas de experiências passadas, mas a experiências atuais em uma sessão singular. Assim, os questionários estruturados destacam os tipos de conteúdos que aparecem nas visões da ayahuasca em geral, ao passo que, por contraste, os dados de sessões individuais refletem a efetiva distribuição desses conteúdos. Considerando-se essa diferença básica, de um ponto de vista estritamente técnico, os dados coletados por meio de questionários estruturados não são diretamente comparáveis aos extraídos dos relatos mais completos das sessões (como aqueles relativos à minha pessoa e os corpora de Polari e Amaringo - ver adiante), nem aos coletados nas entrevistas não estruturadas.

\section{Os corpora da literatura}

Na literatura só há dois corpora em que se descreve um número considerável de visões da ayahuasca experimentadas por um indivíduo; eles definem, respectivamente, os conjuntos no 2 e no 3 da presente análise. O primeiro deles é o de todas as sessões de ayahuasca narradas por Polari - um dos líderes da Igreja do Santo Daime - em sua obra autobiográfica, O livro das mirações (Polari 1984). Esse corpus consiste em 41 sessões e será denominado corpus Polari. O segundo corpus (conjunto oㅡ 3) é o das pinturas do xamã e artista peruano Pablo Amaringo e apresentado em Luna e Amaringo (1993). Minha análise cobre 45 das 48 pinturas reproduzidas no livro. Três pinturas foram excluídas: duas que não retratam visões, mas o contexto em que as sessões se realizam, e uma que representa uma lenda mitológica e que tem estilo muito diferente de todas as outras pinturas do corpus. Esse conjunto de dados será designado co- 
mo corpus Amaringo. Note-se que a codificação das pinturas de Amaringo foi feita paralelamente à consulta ao texto que as acompanha em Luna e Amaringo (1993).

\section{Outros dados extraídos da literatura antropológica}

Durante minha pesquisa, examinei todos os relatos diretos que pude encontrar na literatura acerca das visões da ayahuasca. Incluo aqui dois conjuntos desses relatos. O primeiro, que forma o conjunto no 11 da presente análise, consiste em 22 narrativas de não-indígenas que consumiram ayahuasca até 1980. Esse conjunto inclui quase todos os relatos diretos dos primeiros viajantes e estudiosos. Minha impressão é que esses primeiros relatos são bem diferentes de muitos que se publicam hoje. Pessoalmente, considero-os similares, em estilo, aos dados que eu mesmo registrei. Em contraste, muitas narrativas mais recentes sobre as visões me parecem bastante embelezadas; elas também parecem contaminadas por uma familiaridade prévia com outras narrativas da literatura ${ }^{6}$. Os relatos desse conjunto são os seguintes: o do funcionário público equatoriano Villavicencio (1858); o do antropólogo Koch-Grünberg (1921); quatro relatos de pacientes das experiências do médico Fischer Cardenas (1923) para sua tese de doutorado (ao que parece, o primeiro estudo científico a ser realizado sobre a ayahuasca); a descrição feita pelo coronel Morales e citada em Rouhier (1924); os relatos dos escritores Burroughs e Ginsberg (1963), tal como se lêem nas Yage Letters (tratados separadamente); o do colono-mercador Kusel (1965); quatro relatos de brancos, com data entre 1950 e meados da década de 70, citados por Taussig (1987), bem como os relatos diretos de investigadores: Reinburg (1965), Waisbard (1969), Rivier e Lindgren (1972), Reichel-Dolmatoff (1975), Deltgen (1978/1979), Harner (1980), Taussig (1987) e Luna (a primeira experiência de Luna com a ayahuasca, que se deu em 1980, está descrita em Luna e Amaringo 1993).

O segundo conjunto extraído da literatura antropológica consiste em transcrições literais de relatos fornecidos individualmente por indígenas; no contexto da presente análise, figura como conjunto № 12. É notável a existência de muito poucos relatos desse tipo. A maioria das descrições de experiências indígenas com a ayahuasca encontrada na literatura consiste em narrativas resumidas que não apresentam informações concretas nem detalhes específicos quanto ao número e identidade dos informantes. Os quinze relatos desse grupo, aqui analisados, são tudo o que 
pude encontrar. Incluem: o relato de um xamã jívaro (Harner 1973c); o relato de Chaves (1958, citado em Harner 1973b); relatos citados em Der Marderosian et alii (1970), Lamb (1971) e Kensinger (1973); três relatos de Langdon (dois em Langdon 1979b e um em Langdon 1992b); o conjunto de descrições apresentadas em memória de Fernando Payaguaje (1983), xamã secoya; um relato citado em Luna (1986a); a descrição da viagem de um aprendiz com seu mestre, recontada por G. Arévalo Valera (1986); e quatro relatos trazidos por Taussig (1987).

\section{Codificação e método de análise}

\section{Considerações semânticas}

Para explicar o modo como esses dados foram codificados, é necessário considerar algumas questões lógico-semânticas relativas à categorização. Um princípio fundamental da psicologia cognitiva é que a categorização é uma projeção humana, e não diz respeito a características intrínsecas do mundo em $\mathrm{si}^{7}$. Por via de regra, as coisas podem ser categorizadas - e correspondentemente classificadas e nomeadas - em diferentes níveis de especificidade; por exemplo, Dumbo é, ao mesmo tempo, um elefante, um mamífero e um animal. Além disso, algumas categorias estão contidas como subconjuntos de outras (por exemplo, elefantes é um subconjunto do conjunto mamíferos, que por sua vez é um subconjunto do conjunto animais). Isso define uma hierarquia lógico-semântica em que as categorias mais gerais estão associadas aos níveis mais altos, ao passo que as categorias mais específicas estão associadas aos níveis mais baixos. Assim, a priori, as categorias relativas aos níveis semânticos mais altos tendem a prevalecer em termos de freqüência.

Os dados foram codificados segundo 213 classificadores elementares. Esse nível de especificidade se mostrou adequado, na medida em que todos os dados relatados por informantes ou mencionados na literatura estão cobertos por algum classificador. Para os propósitos da análise, os elementos básicos de conteúdo foram reunidos em 27 agrupamentos semânticos, relacionados a seguir: materiais pessoais e autobiográficos ${ }^{8} ;$ realeza e figuras religiosas; mamíferos; aves; répteis; criaturas marinhas; insetos; animais não-naturais; criaturas e seres (isto é, aqueles que não são humanos nem animais); paisagens; florestas e jardins; cidades; palácios e templos; objetos artísticos e mágicos; objetos caseiros; veículos de transporte (inclusive naves espaciais); símbolos e inscrições; cenas e imagens de an- 
tigas civilizações; cenas e figuras históricas (ou, simplesmente: a história); figuras e cenas mitológicas (em uma palavra: mitologia); cenas espaciais e planetárias; cenas celestiais; cenas de criação e evolução; seres divinos e semidivinos; encontros com o Divino; cenas de luz suprema; e morte.

Com exceção do primeiro (materiais pessoais e autobiográficos), todos os demais agrupamentos de codificação apresentados constituem as categorias semânticas básicas da presente análise ${ }^{9}$ i por vezes, elas são designadas simplesmente como categorias. De um ponto de vista lógicosemântico, as categorias básicas definem um nível médio; acima delas estão as supercategorias, mais amplas e gerais, e abaixo estão aqueles que aqui são designados como pormenores. Em outras palavras, as categorias básicas estão subsumidas nas supercategorias, enquanto os exemplos ou casos específicos das categorias básicas são os pormenores.

Nos casos pertinentes, cada item relatado foi codificado sob todos os classificadores elementares aplicáveis. Assim, por exemplo, uma coroa real de ouro foi codificada como um objeto, como objeto relativo à realeza e como objeto de ouro. A codificação não foi sensível ao número de vezes em que um item apareceu em uma mesma sessão (ou pintura, no caso de Amaringo). Em outras palavras, um item é contado da mesma forma, quer tenha aparecido uma vez na sessão, quer várias vezes em diversas visões durante a mesma sessão. Desse modo, os valores numéricos apresentados aqui indicam uma porcentagem do total de sessões levantadas nas quais os itens relativos a determinada categoria apareceram em alguma visão; esses valores não dão a ocorrência relativa de tais itens em qualquer sessão de ayahuasca (nem, portanto, no corpus como um todo).

Ao apresentar os resultados, darei atenção às categorias básicas. A apresentação dos resultados no texto vai de par com a apresentação de uma série de tabelas. Em nome da concisão, os termos relativos a algumas categorias figuram, nas tabelas, em variantes mais curtas do que os termos empregados no texto. As freqüências relativas dos diferentes conjuntos de dados são apresentadas em grupos, segundo o método com que foram coligidos. A Tabela 1 contém dados do meu corpus central. Por serem diretamente comparáveis aos meus, os dados dos corpora Polari e Amaringo vêm a seguir, na Tabela 2. A Tabela 3 apresenta os dados dos três conjuntos baseados em questionários estruturados. A Tabela 4 apresenta os dados relativos a sessões específicas. E a Tabela 5 traz os dados baseados em relatos que figuram na literatura antropológica.

Para o meu corpus e o de Polari, as tabelas especificam aquelas categorias que aparecem em mais de $20 \%$ das sessões dos respectivos corpora e os pormenores que aparecem em mais de $10 \%$ deles. Para o cor- 
pus Amaringo, as porcentagens mínimas para inclusão são mais altas $50 \%$ para as categorias e $20 \%$ para os pormenores. Isto se deve ao fato de as pinturas serem muito ricas em detalhes: neste caso, a aplicação de porcentagens mínimas idênticas às adotadas como critério de inclusão para o meu corpus e o de Polari resultaria em tabelas excessivamente longas (e de pouca significação estatística). Com relação aos questionários estruturados, são apresentadas as categorias (básicas e de pormenores) que receberam resposta afirmativa de, no mínimo, 50\% dos informantes nos grupos pesquisados. Os limites de inclusão dos corpora (meu, de Polari e de Amaringo) são mais baixos que os das entrevistas estruturadas; isto se deve ao fato de que estas indagam da experiência total ou acumulada, enquanto aqueles estão baseados em relatos propriamente ditos a respeito de um conjunto de sessões. Quanto ao conjunto das sessões específicas, o limite de inclusão para as categorias e para os pormenores foi de $10 \%$.

Note-se que as porcentagens-limite adotadas aqui foram bastante altas. Isto reflete o fato de os itens mais comuns nas visões da ayahuasca aparecerem em freqüências elevadas. Eu, por exemplo, tive visões de serpentes em quase um quinto das sessões com ayahuasca. Em termos absolutos, este é um fato notável. Para que tenha uma idéia, o leitor pode considerar a freqüência dos elementos de conteúdo mais comuns em seus sonhos: os valores numéricos relativos a estes são bem mais baixos. Conforme mostrado pelo levantamento de Hall e Van de Castle (1966), a freqüência dos elementos de conteúdo, mesmo daqueles mais comuns, chega a meros $15 \%$. Na verdade, esse nível só é atingido por alguns poucos elementos (p. ex., pais, casas, carros); em geral, as freqüências dos elementos mais comuns que aparecem nos sonhos estão entre 3\% e $6 \%$.

Além das porcentagens, as tabelas também apresentam um ordenamento hierárquico das diferentes categorias dentro de cada conjunto de dados. Ao contrário das porcentagens, o ordenamento permite comparações entre conjuntos.

Na maioria dos casos, não faz sentido examinar os valores relativos às supercategorias: eles são altos por definição, pois refletem o nível semântico das categorias, e não os achados empíricos per se. Além disso, de modo geral, a informação pertinente no que concerne a esses valores está indicada pelas porcentagens associadas às categorias básicas subsumidas por elas. Por outro lado, são especialmente instrutivos aqueles casos em que é baixa a freqüência associada a uma supercategoria. Obviamente, os pormenores que apresentam alta freqüência também são significativos. 
Tabela 1

Corpus central (Conj. no 1) $(n=67)$

$\%$

\section{Supercategorias}

Seres humanos

Animais naturais

50,75

O sobrenatural

47,76

Arquitetura

40,30

Objetos

37,31

Plantas

26,87

Biografia pessoal

11,94

\section{Categorias}

Mamíferos

37,31

Objetos artísticos e mágicos

35,82

Aves

28,36

Realeza e figuras religiosas

28,36

Paisagens

26,87

Palácios e templos

Animais não-naturais

25,37

Cenas celestiais

Répteis

23,88

Seres divinos

23,88

Cidades

23,88

Veículos de transporte

22,39

\section{Pormenores}

Felinos

Paisagens aquáticas

19,40

Flores

19,40

Objetos de ouro

17,91

Serpentes

17,91

Procissões

16,42

Mulheres dançando

14,93

Florestas

13,43

Templos

13,43

Seres semidivinos

13,43

Realeza

11,94

Cidades encantadas

11,94

Paisagens abertas

11,94

Palácios

11,94

Anjos e seres diáfanos

10,45

Jardins

10,45

Objetos da realeza 
Tabela 2

\begin{tabular}{|c|c|c|c|}
\hline $\begin{array}{l}\text { Corpus Polari } \\
(\text { Conj. no } 2)(n=41)\end{array}$ & $\%$ & $\begin{array}{l}\text { Corpus Amaringo } \\
\text { (Conj. no } 3)(n=45)\end{array}$ & $\%$ \\
\hline Supercategorias & & Supercategorias & \\
\hline O sobrenatural & 46,34 & Animais naturais & 97,78 \\
\hline Seres humanos & 31,71 & O sobrenatural & 95,56 \\
\hline Objetos & 31,71 & Seres humanos & 82,22 \\
\hline Arquitetura & 26,83 & Plantas & 73,33 \\
\hline Plantas & 14,63 & Objetos & 66,67 \\
\hline Animais naturais & 12,20 & Arquitetura & 42,22 \\
\hline Biografia pessoal & 12,20 & Biografia pessoal & 0,00 \\
\hline Categorias & & Categorias & \\
\hline Seres divinos & 26,83 & Répteis & 91,11 \\
\hline Palácios e templos & 26,83 & Criaturas e seres & 84,44 \\
\hline Criaturas e seres & 24,39 & Realeza e figuras & 73,33 \\
\hline Paisagens & 21,95 & religiosas & \\
\hline Mamíferos & 71,11 & Veículos de transporte & 68,89 \\
\hline Objetos artísticos & 21,95 & Aves & 64,44 \\
\hline \multirow[t]{2}{*}{ e mágicos } & & $\begin{array}{l}\text { Objetos artísticos } \\
\text { e mágicos }\end{array}$ & 62,22 \\
\hline & & Animais não-naturais & 55,56 \\
\hline Pormenores & & Pormenores & \\
\hline Palácios & 21,95 & Serpentes & 88,89 \\
\hline Paisagens abertas & 17,07 & Ninfas & 62,22 \\
\hline Anjos e seres diáfanos & 14,63 & ETs \& espaçonaves & 57,78 \\
\hline Objetos da realeza & 14,63 & Realeza & 53,33 \\
\hline Florestas & 12,20 & Flores & 42,22 \\
\hline Civilizações & 12,20 & Objetos da realeza & 40,00 \\
\hline \multirow[t]{10}{*}{ pré-colombianas } & & Quimera e seres alados & 37,78 \\
\hline & & Cidades encantadas & 35,56 \\
\hline & & Figuras religiosas & 35,56 \\
\hline & & Anjos e seres diáfanos & 26,67 \\
\hline & & Paisagens aquáticas & 26,67 \\
\hline & & Objetos de ouro & 24,44 \\
\hline & & Florestas & 24,44 \\
\hline & & Armaria & 24,44 \\
\hline & & Guias \& guardiães & 22,22 \\
\hline & & Felinos & 22,22 \\
\hline
\end{tabular}


Tabela 3: Questionários Estruturados

\begin{tabular}{|c|c|c|c|c|c|}
\hline $\begin{array}{l}\text { Independentes I } \\
(\text { Conj. no 4) }(n=18)\end{array}$ & $\%$ & $\begin{array}{l}\text { Independentes II } \\
\text { (Conj. } n \circ 5)(n=10)\end{array}$ & $\%$ & $\begin{array}{l}\text { Afiliados } \\
\text { (Conj. } n \circ 6)(n=21)\end{array}$ & $\%$ \\
\hline Supercategorias & & Supercategorias & & Supercategorias & \\
\hline O sobrenatural & 100,0 & O sobrenatural & 100,00 & O sobrenatural & 90,48 \\
\hline Arquitetura & 100,0 & Seres humanos & 90,00 & Arquitetura & 76,19 \\
\hline Animais naturais & 94,44 & Objetos & 90,00 & Objetos & 76,19 \\
\hline Seres humanos & 88,89 & Animais naturais & 80,00 & Seres humanos & 66,67 \\
\hline Plantas & 88,89 & Plantas & 80,00 & Animais naturais & 66,67 \\
\hline Objetos & 88,89 & Biografia pessoal & 70,00 & Plantas & 47,62 \\
\hline Biografia pessoal & 61,11 & Arquitetura & 50,00 & Biografia pessoal & 33,33 \\
\hline Categorias & & Categorias & & Categorias & \\
\hline Palácios e templos & 100,0 & Seres divinos & 90,00 & Palácios e templos & 66,67 \\
\hline Morte & 94,44 & Morte & 80,00 & Seres divinos & 57,14 \\
\hline Aves & 88,89 & Aves & 70,00 & Aves & 52,38 \\
\hline Seres divinos & 88,89 & Antigas civilizações & 70,00 & Paisagens & 52,38 \\
\hline Criaturas e seres & 83,33 & Cenas espaciais & 70,00 & Antigas civilizações & 52,38 \\
\hline Répteis & 83,33 & Objetos artísticos & 70,00 & Objetos artísticos & 52,38 \\
\hline Florestas e jardins & 77,78 & e mágicos & & e mágicos & \\
\hline Realeza e figuras & 72,22 & Mamíferos & 60,00 & & \\
\hline religiosas & & Répteis & 60,00 & & \\
\hline Paisagens & 72,22 & Encontros com & 60,00 & & \\
\hline Veículos & 72,22 & o Divino & & & \\
\hline de transporte & & Realeza e figuras & 60,00 & & \\
\hline Cenas espaciais & 72,22 & religiosas & & & \\
\hline Símbolos & 72,22 & Paisagens & 60,00 & & \\
\hline Objetos artísticos & 72,22 & Criaturas e seres & 50,00 & & \\
\hline e mágicos & & Palácios e templos & 50,00 & & \\
\hline Mamíferos & 66,67 & Símbolos & 50,00 & & \\
\hline Antigas civilizações & 66,67 & & & & \\
\hline Cenas celestiais & 61,11 & & & & \\
\hline Cidades & 55,56 & & & & \\
\hline Animais & 50,00 & & & & \\
\hline não-naturais & & & & & \\
\hline Mitologia & 50,00 & & & & \\
\hline História & 50,00 & & & & \\
\hline Pormenores & & Pormenores & & Pormenores & \\
\hline Serpentes & 83,33 & Felinos & 60,00 & Paisagens aquáticas & 52,38 \\
\hline Anjos e seres & 83,33 & Serpentes & 60,00 & Palácios & 52,38 \\
\hline diáfanos & & Seres semidivinos & 60,00 & & \\
\hline Palácios & 83,33 & Amigos & 60,00 & & \\
\hline Florestas & 72,22 & e conhecidos & & & \\
\hline Felinos & 61,11 & Flores & 60,00 & & \\
\hline Flores & 61,11 & Anjos e seres & 50,00 & & \\
\hline Templos & 61,11 & diáfanos & & & \\
\hline Paisagens aquáticas & 55,56 & Paisagens abertas & 50,00 & & \\
\hline ETs \& espaçonaves & 55,56 & & & & \\
\hline Guias e guardiães & 55,56 & & & & \\
\hline Cenas egípcias & 50,00 & & & & \\
\hline
\end{tabular}


Tabela 4 (a): Por sessão

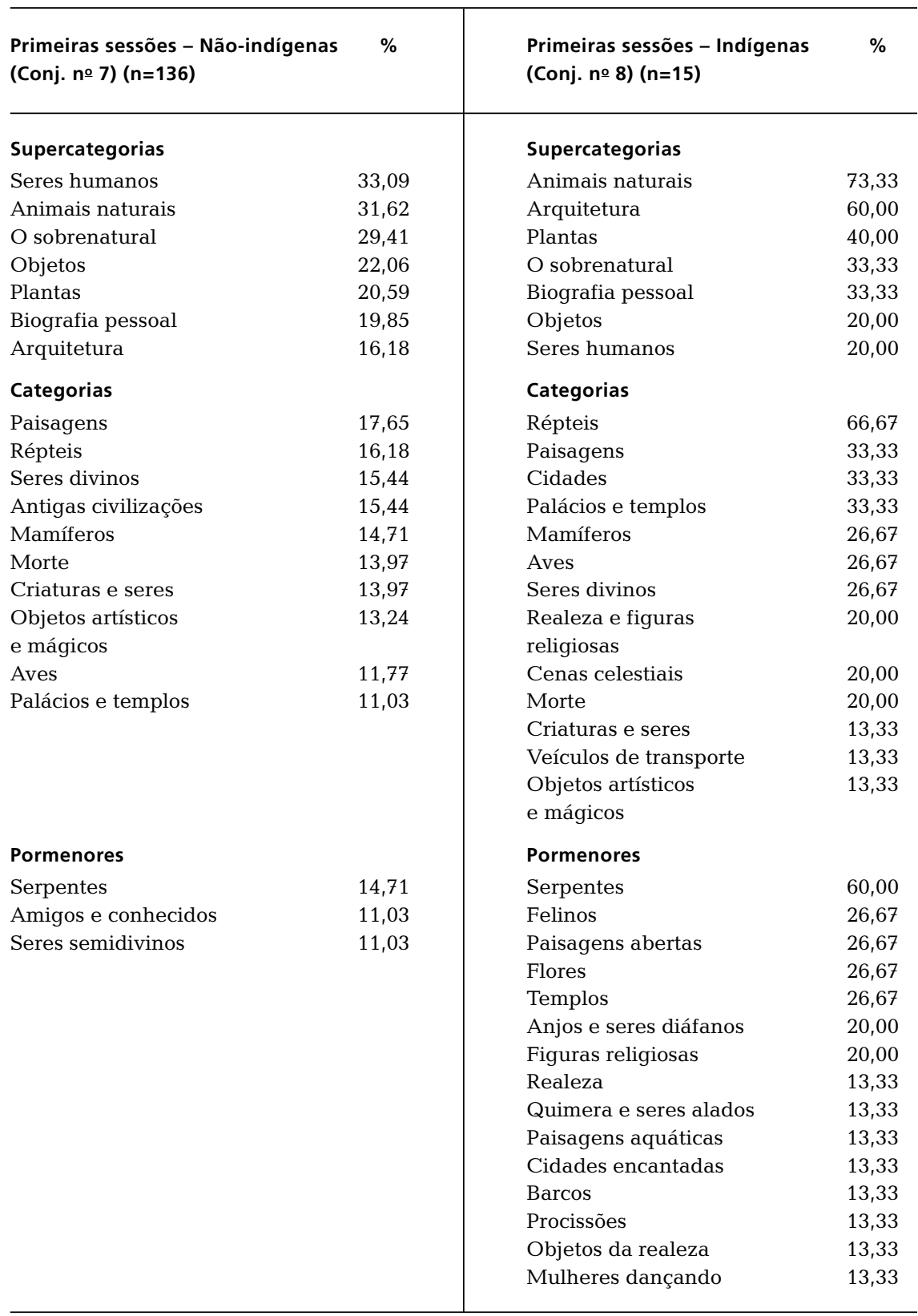


Tabela 4 (b): Por sessão

\begin{tabular}{|c|c|c|c|}
\hline $\begin{array}{l}\text { Primeiras sessões - Não-indígenas } \\
\text { (Conj. no 9) }(n=136)\end{array}$ & $\%$ & $\begin{array}{l}\text { Primeiras sessões - Indígenas } \\
\text { (Conj. no 10) }(n=15)\end{array}$ & $\%$ \\
\hline Supercategorias & & Supercategorias & \\
\hline Seres humanos & 43,14 & Seres humanos & 50,00 \\
\hline Objetos & 39,22 & O sobrenatural & 50,00 \\
\hline O sobrenatural & 33,33 & Animais naturais & 40,91 \\
\hline Animais naturais & 27,45 & Objetos & 22,73 \\
\hline Arquitetura & 17,65 & Arquitetura & 18,18 \\
\hline Biografia pessoal & 9,8 & Plantas & 18,18 \\
\hline Plantas & 5,88 & Biografia pessoal & 9,09 \\
\hline Categorias & & Categorias & \\
\hline Objetos artísticos & 23,53 & Répteis & 27,27 \\
\hline e mágicos & & Seres divinos & 22,73 \\
\hline Seres divinos & 17,65 & Criaturas e seres & 22,73 \\
\hline $\begin{array}{l}\text { Realeza e figuras } \\
\text { religiosas }\end{array}$ & 17,65 & $\begin{array}{l}\text { Objetos artísticos } \\
\text { e mágicos }\end{array}$ & 22,73 \\
\hline Criaturas e seres & 15,69 & Realeza e figuras & 22,73 \\
\hline Mamíferos & 15,69 & religiosas & \\
\hline Répteis & 13,73 & Paisagens & 18,18 \\
\hline Morte & 13,73 & Mamíferos & 18,18 \\
\hline $\begin{array}{l}\text { Encontros com } \\
\text { o Divino }\end{array}$ & 11,77 & Cenas de luz & 13,64 \\
\hline Antigas civilizações & 11,77 & & \\
\hline Cenas celestiais & 11,77 & & \\
\hline História & 11,77 & & \\
\hline Pormenores & & Pormenores & \\
\hline Serpentes & 13,73 & Serpentes & 27,27 \\
\hline \multirow[t]{5}{*}{ Seres semidivinos } & 13,73 & Seres semidivinos & 22,73 \\
\hline & & Procissões & 13,64 \\
\hline & & Figuras religiosas & 13,64 \\
\hline & & Flores & 13,64 \\
\hline & & Objetos de ouro & 13,64 \\
\hline
\end{tabular}


Tabela 5: A literatura antropológica

\begin{tabular}{|c|c|c|c|}
\hline $\begin{array}{l}\text { Relatos antropológicos - Brancos } \\
\text { (Conj. no 11) }(n=22)\end{array}$ & $\%$ & $\begin{array}{l}\text { Relatos antropológicos - } \\
\text { Indígenas (Conj. no 12) }(n=15)\end{array}$ & $\%$ \\
\hline Supercategorias & & Supercategorias & \\
\hline Animais naturais & 59,09 & Animais naturais & 93,33 \\
\hline O sobrenatural & 45,46 & Objetos & 80,00 \\
\hline Seres humanos & 40,91 & O sobrenatural & 80,00 \\
\hline Objetos & 45,46 & Seres humanos & 60,00 \\
\hline Arquitetura & 36,36 & Plantas & 33,33 \\
\hline Plantas & 36,36 & Arquitetura & 26,67 \\
\hline Biografia pessoal & 18,18 & Biografia pessoal & 6,67 \\
\hline Categorias & & Categorias & \\
\hline Mamíferos & 40,91 & Criaturas e seres & 73,33 \\
\hline Répteis & 36,36 & Répteis & 66,67 \\
\hline Paisagens & 36,36 & Mamíferos & 46,67 \\
\hline Objetos artísticos & 31,82 & Aves & 46,67 \\
\hline e mágicos & & Morte & 46,67 \\
\hline Cenas espaciais & 27,27 & Criaturas marinhas & 40,00 \\
\hline Criaturas e seres & 22,73 & Objetos artísticos & 40,00 \\
\hline História & 22,73 & e mágicos & \\
\hline \multirow[t]{12}{*}{ Morte } & 22,73 & Insetos & 33,33 \\
\hline & & Encontros com o Divino & 33,33 \\
\hline & & Viagens espaciais & 33,33 \\
\hline & & Animais não-naturais & 26,67 \\
\hline & & Paisagens & 26,67 \\
\hline & & Cidades & 26,67 \\
\hline & & Mitologia & 26,67 \\
\hline & & Símbolos & 26,67 \\
\hline & & Seres divinos & 20,00 \\
\hline & & $\begin{array}{l}\text { Realeza e figuras } \\
\text { religiosas }\end{array}$ & 20,00 \\
\hline & & Veículos de transporte & 20,00 \\
\hline & & Cenas celestiais & 20,00 \\
\hline Pormenores & & Pormenores & \\
\hline Serpentes & 31,82 & Serpentes & 66,67 \\
\hline Paisagens abertas & 31,82 & Objetos de ouro & 26,87 \\
\hline \multirow[t]{7}{*}{ Felinos } & 22,73 & Felinos & 20,00 \\
\hline & & Anjos e seres diáfanos & 20,00 \\
\hline & & Paisagens aquáticas & 20,00 \\
\hline & & Barcos & 20,00 \\
\hline & & Procissões & 20,00 \\
\hline & & Objetos da realeza & 20,00 \\
\hline & & Armaria & 20,00 \\
\hline
\end{tabular}




\section{Análise comparativa}

Para cada conjunto de dados, todas as categorias foram ordenadas segundo freqüência decrescente e receberam valores numéricos correspondentes (em outras palavras, o número 1 indica a categoria mais freqüente em determinado conjunto). Para que as comparações baseadas nesse ordenamento sejam significativas, é necessário que as populações envolvidas não sejam muito pequenas. Obviamente, se a diferença de posição se resume a uma diferença de um ou dois informantes, ela não tem maior significado. E, certamente, um mesmo número de posição tem significados bem diferentes conforme a contagem seja feita em uma população grande ou pequena. À luz destas considerações, decidi excluir os dados relativos a sessões específicas (conjunto no 10), bem como aqueles concernentes às primeiras sessões relatadas por indígenas (conjunto oㅡ 8), e agrupei os três conjuntos baseados em questionários (nos 4,5 e 6) ${ }^{10}$. Devido a considerações similares sobre o tamanho da amostragem, também excluí desta análise os conjuntos associados aos relatos presentes na literatura antropológica (nos 11 e 12). Resultaram seis conjuntos (meu corpus e os de Polari e Amaringo, dados de questionários, primeira sessão e melhor sessão), cada um baseado em, no mínimo, quarenta sessões e/ou informantes. Os números de posição relativos a esses conjuntos são apresentados na Tabela 6 . Note-se que, dentro de um conjunto, é possível que mais de uma categoria tenha o mesmo valor de freqüência (em outras palavras, pode haver empate entre categorias) e, por isso, várias categorias podem ter o mesmo número de posição.

As posições das categorias foram objeto de duas medidas comparativas. A primeira indica o número de conjuntos em que determinada categoria aparece entre as cinco primeiras posições - o valor máximo possível para essa medida é, obviamente, igual à quantidade total de conjuntos submetidos à comparação, a saber, 6 (dentre seis conjuntos). A segunda medida indica a posição média de cada categoria no total dos seis conjuntos; seu máximo possível é 1. Os valores das duas medidas estão nas duas colunas mais à direita na Tabela 6. Para a primeira medida, o valor máximo obtido foi 4 (i.e., a categoria apareceu entre as cinco primeiras posições em quatro dos seis conjuntos comparados). As categorias para as quais foi obtido esse valor são: realeza e figuras religiosas; mamíferos; répteis; paisagens; objetos de arte e de magia; civilizações antigas; e seres divinos. Quanto à segunda medida, o valor mais alto foi 4,0, e as seguintes categorias tiveram valores entre 4,0 e 5,0 (inclusive): objetos de arte e magia; mamíferos; répteis; seres divinos; e figuras religiosas e 
Tabela 6: Freqüências e posições médias*

\begin{tabular}{|c|c|c|c|c|c|c|c|c|}
\hline & $\begin{array}{l}\text { Conj. no } 1 \\
\text { BS }(n=67)\end{array}$ & $\begin{array}{l}\text { Conj. no } 2 \\
\text { Polari } \\
(n=41)\end{array}$ & $\begin{array}{l}\text { Conj. no } 3 \\
\text { Amaringo } \\
(n=45)\end{array}$ & $\begin{array}{l}\text { Conjs. no 4, 5, } 6 \\
\text { Questionário } \\
(n=49)\end{array}$ & $\begin{array}{l}\text { Conj. } n \circ \mathbf{7} \\
\text { Primeiras } \\
\text { sessões }(n=136)\end{array}$ & $\begin{array}{l}\text { Conj. } \mathbf{n o} 9 \\
\text { Melhores } \\
\text { sessões }(n=51)\end{array}$ & $\begin{array}{l}\text { Número de } \\
\text { ocorrências entre } \\
\text { os } 5 \text { primeiros }\end{array}$ & $\begin{array}{l}\text { Média } \\
\text { total de } \\
\text { posição }\end{array}$ \\
\hline & Posição & Posição & Posição & Posição & Posição & Posição & & Posição \\
\hline Biografia pessoal & 12 & 7 & 19 & 5,7 & 1 & 6 & 1 & 8,5 \\
\hline Realeza e figuras religiosas & 3 & 5 & 3 & 5,3 & 11 & 2 & 4 & 4,9 \\
\hline Mamíferos & 1 & 9 & 4 & 5,7 & 5 & 3 & 4 & 4,6 \\
\hline Aves & 3 & 12 & 6 & 3 & 8 & 8 & 2 & 6,7 \\
\hline Répteis & 6 & 10 & 1 & 4 & 3 & 4 & 4 & 4,7 \\
\hline Criaturas marinhas & 15 & 12 & 15 & 10 & 17 & 9 & & 13 \\
\hline Insetos & 15 & 11 & 14 & 10,3 & 13 & 9 & & 12,1 \\
\hline Animais não-naturais & 5 & 12 & 8 & 10,3 & 12 & 9 & 1 & 9,4 \\
\hline Criaturas e seres & 11 & 2 & 2 & 5,7 & 6 & 3 & 3 & 5 \\
\hline Paisagens & 4 & 3 & 12 & 4,3 & 2 & 7 & 4 & 5,4 \\
\hline Florestas e jardins & 8 & 7 & 13 & 6 & 10 & 8 & & 8,7 \\
\hline Cidades & 6 & 12 & 10 & 6,7 & 15 & 8 & & 9,6 \\
\hline Palácios e templos & 4 & 1 & 11 & 2,3 & 9 & 6 & 3 & 5,6 \\
\hline Objetos artísticos e mágicos & 2 & 3 & 7 & 4 & 7 & 1 & 4 & 4 \\
\hline Objetos caseiros & 15 & 11 & 12 & 10,7 & 16 & 10 & & 12,5 \\
\hline Veículos de transporte & 7 & 10 & 5 & 7 & 16 & 8 & 1 & 8,8 \\
\hline Símbolos & 15 & 6 & 18 & 5,3 & 10 & 6 & & 10,1 \\
\hline Antigas civilizações & 8 & 4 & 14 & 4,3 & 4 & 5 & 4 & 6,6 \\
\hline História & 12 & 10 & 19 & 8,3 & 12 & 5 & 1 & 11,1 \\
\hline Mitologia & 9 & 12 & 9 & 9,7 & 16 & 9 & & 10,8 \\
\hline Cenas espaciais & 10 & 6 & 16 & 5,3 & 12 & 7 & & 9,4 \\
\hline Cenas celestiais & 5 & 7 & 17 & 8,3 & 14 & 5 & 2 & 9,4 \\
\hline Criação e evolução & 13 & 12 & 19 & 10 & 16 & 6 & & 12,7 \\
\hline Seres divinos & 6 & 1 & 13 & 2 & 4 & 2 & 4 & 4,7 \\
\hline Encontros com o Divino & 14 & 8 & 19 & 8,7 & 12 & 5 & 1 & 11,1 \\
\hline Cenas de luz & 16 & 9 & 19 & 10,7 & 14 & 8 & & 12,8 \\
\hline Morte & 11 & 6 & 14 & 4,3 & 6 & 4 & 2 & 7,6 \\
\hline
\end{tabular}

'O sublinhado indica resultados acima do limite mínimo. 
de realeza. A interseção dessas duas listas abrange as categorias de figuras religiosas e de realeza; mamíferos; répteis; objetos de arte e magia, e seres divinos. Esta afirmação constitui um resumo conciso dos conteúdos mais comuns observados nas visões da ayahuasca.

Foram feitas análises similares sobre os pormenores das visões. A observação mais interessante é que as serpentes são o pormenor mais freqüente em todo o universo pesquisado. Com exceção do corpus Polari, esse elemento aparece entre as primeiras posições das listas de todos os conjuntos de dados: ele foi o primeiro em todos os conjuntos, salvo o conjunto no 10, no qual aparece em segundo.

Determinadas comparações de mão dupla são dignas de nota. A primeira concerne aos três conjuntos de relatos detalhados fornecidos, cada um, por um indivíduo - eu, Polari e Amaringo. Em primeiro lugar, considerem-se os meus dados e os de Amaringo. Devido ao fato de as pinturas de Amaringo serem extremamente ricas em pormenores (muito mais ricas do que uma sessão média do meu corpus central), os valores-limite das porcentagens e dos números de posição, discutidos acima, não fazem justiça ao corpus por elas constituído: nele, há mais categorias com altas freqüências do que no corpus das minhas visões; assim, no corpus Amaringo, algumas categorias que não atingem os pontos-limite até aqui considerados são, ainda assim, representadas com muita freqüência. Em função dessas observações, ao fazer uma comparação direta entre meus dados e os de Amaringo, abaixei os pontos-limite destes, de $50 \%$ para $25 \%$ (o ponto-limite dos meus dados permaneceu tal como na Tabela 1). Com essa mudança de critério, nos dados relativos a Amaringo passa a haver quatorze categorias dentro do limite de inclusão (em vez de oito, tal como consta na Tabela 2). Dessas quatorze categorias, apenas três não aparecem acima do limite mínimo em meu corpus central - criaturas e seres; mitologia; e florestas e jardins. E, inversamente, das doze categorias que no meu corpus estão acima do limite mínimo para inclusão, apenas uma, a das cenas celestiais, não aparece acima do mínimo no corpus de Amaringo. Penso que essa similaridade entre meu corpus e o de Amaringo é de fato notável. Semelhanças entre esses dois corpora também são encontradas no nível dos pormenores. Em ambos os conjuntos de dados, há, respectivamente, 17 e 23 pormenores que alcançaram ou ultrapassaram 10\% (mais uma vez, o limite de inclusão foi abaixado para os dados relativos a Amaringo, ajustando-o ao dos meus dados). Destes, treze eram comuns a ambos os conjuntos.

Passando à comparação entre o meu corpus e o de Polari, os limites aplicados acima (i.e., nas Tabelas 1 e 2, respectivamente) foram manti- 
dos. Nos dados relativos a Polari, há cinco categorias acima do mínimo de inclusão; nos meus há, como se viu, doze. Dessas cinco categorias do corpus Polari, apenas uma, criaturas e seres, não figura acima do limite mínimo entre meus dados; e das categorias que aparecem em meus dados acima do mínimo, oito (ou seja, dois terços) não estão acima do mínimo correspondente em Polari. Claramente, esse quadro é bem diferente daquele que se revela com a comparação entre meus dados e os de Amaringo. Tendo a atribuir tal diferença ao fato de que os dados de Polari são, de fato, algo discrepantes de todos os demais conjuntos examinados aqui. Em primeiro lugar, note-se que o conjunto de Polari é, dentre todos, aquele com o menor número de categorias acima do limite mínimo. Em segundo, o conjunto de Polari é o único em que nem serpentes nem felinos figuram de modo conspícuo e são, a bem da verdade, raros nesse corpus. De fato, esse conjunto é o único no qual a supercategoria dos animais é a de freqüência mais baixa. Em contraste, no corpus Polari, a categoria dos seres divinos vem na posição mais alta. Faz sentido atribuir tal fato ao contexto religioso em que Polari consumiu a ayahuasca (e, também, às notáveis qualidades espirituais da sua pessoa). Sem negar esse aspecto, quero chamar a atenção do leitor para o fato de que os seres divinos são comuns em todos os conjuntos de dados examinados aqui e que na grande maioria dos casos constituem uma das categorias de mais alta posição. Assim, o contexto religioso pode certamente ter seus efeitos, mas o material de cunho religioso que aparece nas visões não depende absolutamente de tal contexto (tampouco, aliás, de experiências prévias com a infusão). No que diz respeito aos pormenores, mais uma vez, os dados de Polari formam um leque menos extenso que os meus: encontram-se nos seus dados seis pormenores acima do limite de $10 \%$, contra dezessete nos meus; desses seis, cinco são comuns aos dois subconjuntos.

Ao analisar os dados coletados por meio de questionários - conjuntos nos 4 (independentes I), 5 (independentes II) e 6 (afiliados) -, verificamos, respectivamente, 20, 14 e 6 categorias acima do valor mínimo de inclusão. A interseção dos três subconjuntos é máxima, no sentido de que todas as seis categorias do menor dos três conjuntos - o dos afiliados aparecem na interseção (em outras palavras, também aparecem nos dois outros conjuntos). Outras sete categorias (perfazendo um total de treze em um máximo possível de quatorze) são comuns aos dois grupos de independentes.

Também os conjuntos relativos a sessões específicas (nํㅗ 7, 8, 9 e 10) permitem comparações diretas. Eles têm, respectivamente, dez, treze, onze e oito categorias acima do limite mínimo de inclusão. A interseção 
dos quatro subconjuntos contém cinco categorias (isto é, aproximadamente metade, ou mais, do número de categorias em cada subconjunto): mamíferos; répteis; criaturas e seres; objetos de arte e mágica; seres divinos. Deve-se, além disso, notar que, restritamente às melhores sessões, as categorias cujas freqüências estão acima do limite mínimo são: encontros com o Divino; cenas celestiais; e figuras e cenas históricas. Em outras palavras, as sessões caracterizadas pelos bebedores como suas melhores experiências tendem a incluir elementos de conteúdo religioso e/ou espiritual. A comparação dos quatro conjuntos no plano dos pormenores mostra que todos incluem serpentes.

Por fim, considerem-se os dados relativos às primeiras sessões. É significativo que, tanto para informantes indígenas quanto para não-indígenas, elas revelem categorias de conteúdo típicas das visões da ayahuasca em geral. Compreendem elementos fantasmagóricos não relacionados a experiências específicas de vida ou ao background cultural dos informantes. Entre eles aparecem: répteis; palácios e templos; objetos de arte e magia; seres divinos. É também relativamente comum, nas primeiras sessões, a visão de pessoas conhecidas.

\section{Sonhos}

Além das visões da ayahuasca, também examinei dois corpora de sonhos: 33 dos meus próprios sonhos e todos os 60 sonhos mencionados em $A$ interpretação dos sonhos (Freud 1953[1900]); destes, 25 são do próprio Freud e 35 foram relatados a ele por outras pessoas.

A análise dos sonhos foi realizada de maneira idêntica à das visões da ayahuasca. No entanto, os dados exigiram o acréscimo de várias categorias: membros da família (distinguidos das pessoas conhecidas), acontecimentos do dia ou do dia anterior (referidos aqui como acontecimentos recentes), detalhes aparentemente sem significado, como números de telefone ou certas palavras proferidas um ou dois dias antes do sonho. Também foi acrescentada a categoria de "padrões paradoxais", que são os padrões que contrariam a lógica - o caso paradigmático é o da pessoa que no sonho se parece com alguém mas que é reconhecida como sendo outra.

A Tabela 7 apresenta as categorias de conteúdo mais comuns nos três conjuntos de sonhos de modo similar ao empregado para as visões da ayahuasca acima.

As principais observações valem igualmente para todos os três conjuntos: a maior parte dos elementos vistos nos sonhos são seres humanos, 
Tabela 7: Sonhos

\begin{tabular}{|c|c|c|c|c|c|}
\hline $\begin{array}{l}\text { Sonhos do autor } \\
(n=33)\end{array}$ & $\%$ & $\begin{array}{l}\text { Sonhos de Freud } \\
(n=25)\end{array}$ & $\%$ & $\begin{array}{l}\text { Relatados por Freud } \\
(n=35)\end{array}$ & $\%$ \\
\hline \multicolumn{2}{|l|}{ Supercategorias } & \multicolumn{2}{|l|}{ Supercategorias } & \multicolumn{2}{|l|}{ Supercategorias } \\
\hline Seres humanos & 81,82 & Seres humanos & 84,00 & Seres humanos & 82,86 \\
\hline Biografia pessoal & 60,61 & Biografia pessoal & 72,00 & Biografia pessoal & 60,00 \\
\hline Objetos & 54,55 & Objetos & 68,00 & Objetos & 57,14 \\
\hline Arquitetura & 48,48 & Arquitetura & 56,00 & Arquitetura & 31,43 \\
\hline Plantas & 12,12 & Plantas & 12,00 & Plantas & 20,00 \\
\hline Animais naturais & 3,03 & Animais naturais & 4,00 & Animais naturais & 11,43 \\
\hline O sobrenatural & 3,03 & O sobrenatural & 4,00 & O sobrenatural & 2,86 \\
\hline \multicolumn{2}{|l|}{ Categorias } & \multicolumn{2}{|l|}{ Categorias } & \multicolumn{2}{|l|}{ Categorias } \\
\hline Itens & 45,46 & Eventos diários & 44,00 & Família & 40,00 \\
\hline \multicolumn{2}{|l|}{ não-significativos } & Família & 32,00 & Eventos diários & 31,43 \\
\hline Cidades & 21,21 & Padrões paradoxais & 28,00 & Itens & 25,71 \\
\hline Objetos caseiros & 21,21 & Itens & 20,00 & não-significativos & \\
\hline Símbolos & 18,18 & \multicolumn{2}{|l|}{ não-significativos } & Objetos caseiros & 20,00 \\
\hline Padrões paradoxais & 18,18 & Objetos caseiros & 20,00 & Paisagens & 20,00 \\
\hline Objetos artísticos & 12,12 & Paisagens & 16,00 & Veículos & 17,14 \\
\hline \multicolumn{2}{|l|}{ e mágicos } & Veículos & 16,00 & \multicolumn{2}{|l|}{ de transporte } \\
\hline Família & 12,12 & de transporte & & Padrões paradoxais & 17,14 \\
\hline \multirow[t]{5}{*}{ Símbolos } & \multirow[t]{5}{*}{16,00} & Cidades & 16,00 & \multirow[t]{5}{*}{$\begin{array}{l}\text { Cenas de conteúdo } \\
\text { sexual }\end{array}$} & \multirow[t]{5}{*}{14,29} \\
\hline & & Morte & 16,00 & & \\
\hline & & $\begin{array}{l}\text { Realeza e figuras } \\
\text { religiosas }\end{array}$ & 12,00 & & \\
\hline & & História & 12,00 & & \\
\hline & & $\begin{array}{l}\text { Objetos artísticos } \\
\text { e mágicos }\end{array}$ & 12,00 & & \\
\hline Pormenores & & Pormenores & & Pormenores & \\
\hline \multirow[t]{2}{*}{ Amigos e conhecidos } & \multirow[t]{2}{*}{54,55} & \multirow[t]{2}{*}{ Amigos e conhecidos } & \multirow[t]{2}{*}{72,00} & Amigos e conhecidos & 60,00 \\
\hline & & & & Paisagens abertas & 14,29 \\
\hline
\end{tabular}

componentes da biografia pessoal e objetos. Significativamente, esse padrão é oposto ao que encontramos nas visões da ayahuasca: os elementos menos freqüentes nos sonhos são alguns dos mais usuais nelas. Inversamente, os elementos relativos à vida pessoal do sujeito são muito comuns nos sonhos mas relativamente infreqüentes nas visões.

É especialmente interessante a comparação entre meus sonhos e minhas visões. Praticamente não há coincidências na distribuição dos elementos de conteúdo nestas e naqueles. Com exceção da supercategoria dos seres humanos, os elementos da biografia pessoal são os itens mais usuais do conteúdo dos sonhos - categoria de freqüência especialmente 
baixa, nas visões. A categoria da arquitetura é comum aos meus sonhos e às minhas visões. Mas nas visões da ayahuasca a maioria dos elementos dessa categoria são edifícios especiais — na verdade, quase todos são ou bem palácios e templos ou construções mágicas —, ao passo que nos sonhos nenhuma das construções é desse tipo. Todas as demais categorias que predominam nas minhas visões são raras ou ausentes em meus sonhos.

Em suma, as visões da ayahuasca são muito diferentes dos sonhos. Em geral, os sonhos têm a ver com os acontecimentos e interesses da vida corrente do sujeito, enquanto as visões - especialmente quando intensas - têm a ver com mundos que parecem bastante estranhos às experiências da vida ordinária. É geralmente admitido o fato de que algumas pessoas têm sonhos mais intensamente fantasmagóricos, e que tais sonhos são especialmente comuns entre os sonhos lúcidos. Eu mesmo, no entanto, quase nunca tive sonhos assim; nem são eles os que prevalecem para Freud e seus informantes.

\section{Resumo dos resultados e visão geral}

Para obter um quadro geral dos resultados aqui relatados, resumirei alguns padrões mais salientes, tal como são revelados pela presente análise comparativa.

Em primeiro lugar, notamos que algumas categorias de conteúdo aparecem em posição elevada em todos ou quase todos os conjuntos de dados examinados aqui. É significativo que essas categorias incluam elementos que não têm relação com a vida e a história pessoal dos bebedores. Destacam-se entre eles animais de toda sorte, criaturas e seres fantasmagóricos, figuras religiosas e de realeza, objetos de arte e magia, e seres divinos. Sublinhe-se que tais conteúdos também aparecem em relatos da primeira sessão de iniciantes sem nenhum conhecimento ou contato prévio com a ayahuasca. Por vezes, há grande semelhança até mesmo entre descrições específicas de certos elementos de conteúdo, feitas por diferentes informantes. Além disso, tomados em sua totalidade, os elementos de conteúdo mais comuns nos relatos parecem definir um quadro único e coerente, ligado, em grande parte, ao mundo do fantástico, do maravilhoso e do encantado. Em linhas gerais, esse quadro aparece em todos os conjuntos de dados analisados aqui: ele se manifesta em relatos feitos por pessoas que não se conhecem mutuamente, vêm de diferentes lugares e têm diversas origens pessoais e socioculturais. 
Destacarei alguns padrões específicos. Em primeiro lugar, à exceção do corpus Polari, elementos ligados ao mundo natural têm posição elevada em todos os conjuntos de dados - encontram-se entre eles alguns dos elementos mais freqüentes, como serpentes, felinos e aves. Nota-se que elementos assim relacionados à natureza são muito freqüentes, inclusive nas visões de indivíduos (como eu mesmo e a maioria dos informantes aqui considerados) cujo background pessoal e cultural é nitidamente urbano (portanto, sem ligação com a Amazônia). Mas, ao mesmo tempo, alguns dos elementos mais comuns que aparecem nos dados não pertencem à natureza, mas à cultura: em especial os objetos de arte e magia (geralmente, preciosos) e vários complexos arquitetônicos. Tais elementos também se destacam muito nas pinturas de Amaringo e nos relatos de indígenas. Não posso assegurar que essas pessoas nunca tenham visto edifícios ou retratos destes, mas com certeza é bastante improvável que tenham alguma vez, na vida real, visto edifícios esplendidamente elaborados e com suntuosos ornatos artísticos, como os que a ayahuasca lhes apresentou em suas visões.

Cabe também um comentário sobre aqueles elementos que são relativamente raros nas visões. Embora alguns aspectos da experiência da ayahuasca possam estar relacionados à biografia individual e a assuntos pessoais, não é este o caso na maioria das vezes. Significativamente, elementos de natureza pessoal ou autobiográfica são comuns apenas nos relatos dos iniciantes, tanto indígenas quanto não-indígenas. Com a ampliação da experiência, ao que parece, tal conteúdo torna-se cada vez menos freqüente. São também bastante raros os objetos de uso doméstico nas visões.

Ao longo de toda a discussão precedente, focalizei as recorrências transpessoais que se manifestam na distribuição de elementos de conteúdo singulares. No entanto, os dados levantados aqui também são instrutivos por definirem, na sua totalidade, o espaço semântico das visões da ayahuasca. Esse espaço abrange quatro domínios principais. O primeiro é o domínio da natureza. Como foi repetidamente apontado na discussão precedente, animais são alguns dos elementos mais comuns nas visões. Paisagens naturais e cenas de florestas e jardins são também freqüentes. O segundo domínio é o da cultura. Suas principais manifestações são as cidades majestosas, a magnificência da realeza, os vários produtos da criação artística, religião e magia. Usualmente, o que aparece nas visões não são conteúdos relativos ao meio sociocultural do próprio bebedor, mas sim aqueles associados a civilizações antigas. Além disso, a maioria dos objetos e artefatos, nas visões, são esplendidamente orna- 
mentados ou preciosos (ou ambos). Similarmente, a maior parte dos edifícios que aparecem são palácios ou templos, e entre os seres humanos muitos são reis e rainhas, ou figuras religiosas e pessoas de ascendência espiritual. O terceiro é o mundo da fantasia. Compreende terras mágicas e encantadas e é habitado por todo tipo de criatura, que não são nem seres humanos nem animais (no sentido naturalístico). Como foi indicado, os objetos e cenas que de ordinário aparecem nas visões não são mundanos; estão com freqüência associados à mitologia, aos contos de fadas e à magia. O quarto domínio é o do espiritual e do sobrenatural. As visões da ayahuasca muitas vezes revelam à pessoa reinos celestiais. Nestes, comumente, aparecem seres divinos e semidivinos. O domínio sobrenatural é via de regra associado a significados espirituais e metafísicos que não são normalmente vistos ou considerados.

\section{Temas}

No início deste artigo, esclareci que elementos de conteúdo como os aqui examinados constituem apenas um aspecto do conteúdo das visualizações provocadas pela ayahuasca, aspecto que caracterizei como "micro". Além dele, há o nível "macro" — o dos temas. Nem todas as visualizações promovidas pela ayahuasca dão margem a uma análise temática. A maioria das visualizações que as pessoas experimentam consiste em elementos figurativos isolados: uma pessoa ou um animal aparece diante delas, ou uma paisagem ou edificação são vistos de relance. Em geral, esses quadros singulares (no sentido cinematográfico, do fotograma) são breves e não comportam complexidade semântica nem desenvolvimento narrativo. Para que uma análise macro, temática, seja validamente aplicável, as visões devem consistir em mais que tomadas fragmentárias (mais uma vez, emprego a linguagem cinematográfica), elas devem consistir em cenas inteiras que tenham extensão temporal e exibam complexidade semântica. As cenas grandiosas impressionam bastante os bebedores, apresentam narrativas elaboradas e trazem mensagens a que os sujeitos atribuem importância. A sensação é que a experiência visionária não é meramente visual, mas também ideacional, e por ela algum ensinamento é transmitido à pessoa que vê.

Não são todas as pessoas que têm visões caracterizáveis como cenas grandiosas, mas aquelas que as têm relatam temas similares. Há, em primeiro lugar, temas relativos à pessoa individual. Eles têm a ver com a autocompreensão psicológica (os informantes usam bastante o termo "psi- 
canalítico"), com questões e decisões específicas da vida pessoal e com a maneira de conduzi-la em geral. Em segundo lugar estão os temas concernentes à vida dos seres humanos como indivíduos (mas que não são específicos a esta ou àquela pessoa). Estão aí compreendidos a experiência da morte e novo nascimento, insights sobre o significado geral da vida humana, moralidade e ética. Em terceiro lugar estão os temas próprios à experiência de vida dos seres humanos na qualidade de membros de um grupo maior, a espécie Homo sapiens. Incluem-se aí os temas do sofrimento humano, da história e seu significado, do dilema humano como dialética entre natureza e cultura, a natureza da mente e da consciência e o lugar da existência humana na grande estrutura do ser. Em quarto lugar está o nível supra-humano. Compreende a mitologia, reinos não naturalísticos freqüentemente referidos como "astrais" (p. ex., experiências em que os céus se abrem e seres podem ser vistos), experiências em que o sujeito sente que encontra o Divino e experiências nas quais o papel central é de uma luz sobrenatural. Em quinto lugar estão os temas metafísicos. Mencionem-se especialmente aqueles relacionados à anima mundi - aquela grande substância espiritual ou energia que a pessoa sente ser fonte de toda a Existência e permeá-la, sustentando tudo que há. Ligados a ela estão os temas relativos à natureza do Ser e o mundo das idéias, de tipo platônico. Em sexto lugar encontram-se os temas ligados à criação. Concernem à criação do universo e às forças da natureza, à origem da vida e à evolução biológica, assim como à criação artística (que é humana, mas talvez divinamente inspirada). E, por último, há vários tópicos específicos que parecem ter importância nas visões da ayahuasca: realeza, civilizações antigas (notavelmente, o Egito e as civilizações précolombianas), a floresta e a natureza da vida animal.

\section{Discussão teórica}

As recorrências apresentadas pelas visualizações com a ayahuasca são especialmente desafiadoras ao entendimento, pois envolvem conteúdos específicos, tanto visuais quanto ideacionais. Por via de regra, universais cognitivos dizem respeito à forma e à estrutura; os casos paradigmáticos são as estruturas sintáticas profundas das línguas naturais, as operações fundamentais da lógica e do raciocínio e os esquemas elementares da categorização. Em contraste, as recorrências apresentadas pela ayahuasca concernem ao conteúdo; nessa qualidade, são especialmente enigmáticas. Poderiam serpentes e felinos, pedras preciosas e palácios serem também 
universais da mente humana? Cognitivistas contemporâneos não estão prontos a dar resposta afirmativa a esta questão. Tampouco as atuais teorias neurofisiológicas sobre o cérebro podem dar conta dessa discussão.

Como deverão ser explicadas as recorrências aqui expostas? Para ser inteiramente honesto, considero-as um mistério e não procurarei oferecer uma explicação definitiva. O que farei, em vez disso, é considerar esses achados à luz de debates e quadros de pensamento da antropologia e da psicologia.

\section{Considerações antropológicas}

Na literatura antropológica, as visualizações proporcionadas pela ayahuasca são com freqüência associadas a qualidades específicas da mente indígena. Assim, em sua introdução à obra antropológica de Reichel Dolmatoff, O xamã e o jaguar (1975), o etnobotânico Schultes escreve:

Já foi dito que a razão da importância de cobras enormes e grandes felinos nas culturas nativas é simplesmente que esses animais, furtivos e fortes, despertam no índio terror e medo. Mas é claro que tal explicação não se sustenta diante de um exame mais profundo. Houve tentativas de explicação "bioquímica": que a grande freqüência de jaguares e outros felinos e de cobras nas descrições dos estados de inebriação por caapi poderia dever-se a uma capacidade dos constituintes do alucinógeno para induzir visões de determinados tipos de objetos. Mas não há sombra de evidência de que exista uma tal especificidade de ação. Fica-se então próximo da certeza de que, subjacente à primazia do jaguar nas culturas, há experiências altamente positivas, antigas e profundamente incrustadas, que são agora parte da mente do aborígene (Schultes 1975:xiii).

Argumento similar é, por exemplo, apresentado por Brüzzi Alves da Silva, para quem os efeitos da ayahuasca relatados por indígenas devem ser explicados pela "fácil excitação da imaginação deles" (1962:262).

Além disso, muito já foi dito na literatura antropológica sobre a relação entre as visualizações com ayahuasca e as tradições e práticas culturais dos povos indígenas que fazem uso da infusão. Encontram-se aqui duas linhas de pensamento. A primeira considera os conteúdos das visualizações da ayahuasca um reflexo das crenças e visões de mundo dos indígenas que a consomem; proposições nesse sentido podem ser encon- 
tradas em Reichel-Dolmatoff (1975; 1978), Langdon (1979b) e Gow (1988). A segunda linha de pensamento defende uma relação inversa e considera as visualizações, e não as crenças culturais, como primárias (ver Furst 1990; Lagrou 1991; 1996; 1998).

Não há como negar que fatores ligados à personalidade e ao background sociocultural de quem bebe ayahuasca podem ter sua parte naquilo que é visto em estado de inebriação. Mas, sem deixar de reconhecê-lo, deve-se ter em conta que muitos aspectos da experiência da ayahuasca são na realidade independentes de antecedentes ou condições pessoais e socioculturais. Observo ainda que as experiências visionárias dos indígenas não são todas iguais. O que se verifica entre os ameríndios é similar ao que ocorre entre ocidentais: eles não são idênticos entre si e também eles estão sujeitos a várias injunções contextuais. Na verdade, a literatura antropológica é extremamente decepcionante a esse respeito: os índios não têm, todos, as mesmas visões! A verdade é que as pessoas não vêem todas as mesmas coisas com a ayahuasca, e as coisas que cada pessoa vê não são sempre as mesmas em todas as sessões de que ela participa - isto vale para todas as pessoas, sejam indígenas ou não. Ademais, as afirmações sobre as visões da ayahuasca e seu conteúdo na literatura antropológica não são acompanhadas de especificações quanto ao número de informantes, freqüência do fenômeno, diferenças pessoais e variações. Em particular, boa parte da própria análise de Reichel-Dolmatoff sobre os efeitos da ayahuasca está baseada nos relatos de um único informante, se bem que com largos conhecimentos e experiência (ver Reichel-Dolmatoff 1971).

Com o juízo de que as visões e a experiência (em geral) da ayahuasca não devem ser caracterizadas em termos específicos aos indígenas e sua cultura, mas sim em termos universais e cognitivos, nossa discussão se volta da antropologia para a psicologia.

\section{Considerações psicológicas}

Com a adoção de uma postura psicológica, a noção que de imediato vem à mente é a de inconsciente. Em particular, notam-se duas espécies de inconsciente: o pessoal e o coletivo; paradigmaticamente, o primeiro é associado a Freud e o segundo, a Jung. Discutirei um e outro.

Se se adotasse uma abordagem freudiana, considerar-se-ia que a ayahuasca traz para o primeiro plano aquilo que de ordinário está oculto nas profundezas da psique da pessoa. Assim, seria de supor que aquilo 
que uma pessoa experimenta, por efeito da infusão, é o reflexo dos seus próprios conflitos e preocupações, desejos e esperanças. Empiricamente, esse não é, em regra, o caso. Os conteúdos das visões da ayahuasca não retratam usualmente histórias de vida particulares dos indivíduos em questão, nem parecem ter relação com elas — seja de modo direto ou simbólico. Em contraste, há muitas coisas nas experiências da ayahuasca que não aparentam ter ligação alguma com a personalidade e a história de vida daqueles que as relatam. Esta afirmação encontra apoio suplementar nas diferenças entre as visões da ayahuasca e os sonhos - como foi acima apontado, quase não há coincidências entre eles. Mais uma vez, os conteúdos dos sonhos geralmente refletem questões pessoais, mas os das visões da ayahuasca, não. Similarmente, objetos domésticos são freqüentemente vistos em sonhos, mas não com a ayahuasca.

Jung $(1960 ; 1969)$ postulou o inconsciente coletivo à luz de considerações muito similares àquelas que estamos aqui discutindo no contexto da ayahuasca. Especificamente, ao descobrir que várias manifestações da vida psíquica - sonhos, visões, fantasias, padrões de insanidade e obras culturais - apresentam recorrências de que não é possível dar conta em termos das histórias de vida dos indivíduos, ele propôs a existência de um nível que é ao mesmo tempo psicológico e coletivo. Prima facie, a abordagem jungiana parece especialmente adequada para a análise da experiência da ayahuasca (ver Furst 1990). No entanto, quando se examinam detalhes, a situação afigura-se diferente. Gostaria de apontar, particularmente, três problemas da versão jungiana. Os dois primeiros são gerais (isto é, não são específicos ao estudo da ayahuasca) e o terceiro é diretamente relacionado às recorrências nas visões da ayahuasca.

Em primeiro lugar, há muito menos na noção de "inconsciente coletivo" do que pode parecer à primeira vista. Postular um inconsciente coletivo equivale a dizer que há fenômenos psicológicos que são inconscientes porém não individuais. Mas note-se que isto não é mais que uma reafirmação daqueles mesmos fenômenos que nos intrigam - o termo "inconsciente coletivo", além de afirmar que tais fenômenos de fato existem, nada explica. Em segundo lugar, a natureza dos arquétipos jungianos está longe de ser clara. São eles mera abstração teórica no nível psicológico? São eles reflexos de estruturas biológicas que se formaram no curso da evolução da espécie? Ou talvez sejam formas de tipo platônico, com status ontológico especial? Essa indeterminação talvez não seja comumente ponderada por aqueles que lêem e/ou seguem Jung, mas não há dúvida quanto a ela - o próprio Jung estava plenamente consciente do fato. Uma leitura cuidadosa dos escritos de Jung revela que ele pes- 
soalmente se preocupava bastante com essas questões (ver, especialmente, Jung 1969 [1954]. Além disso, estava consciente de quão insuficiente era a sua versão dos arquétipos. Se estes não eram meras abstrações teóricas, então, como Jung explicitamente reconheceu, o próprio autor teria muito pouca coisa de substantivo a afirmar sobre eles. Se o nível apropriado de análise é a biologia, faz-se necessário especificar as estruturas e mecanismos biológicos em jogo - e Jung tinha pleno conhecimento de que as ciências da vida, em seu estado de adiantamento naquela época, não ofereciam condições para tanto. Mais ainda: Jung temia que a versão biológica dos arquétipos levasse ao lamarckismo, considerado não científico por praticamente todos os biólogos. Por outro lado, se o nível adequado é o ontológico, somos levados a uma infinidade de problemas metafísicos que desafiaram os filósofos por mais de dois milênios e que ainda não tiveram respostas satisfatórias.

Conforme foi apontado, a terceira falha da formulação de Jung diz respeito especificamente à ayahuasca. As recorrências transpessoais encontradas nas visões são muito diferentes daquelas associadas aos arquétipos jungianos. Estes podem de fato ser ligados à herança comum partilhada por todos os seres humanos e que pode muito bem ter evoluído ao longo da história da espécie. A Grande Mãe, o Velho Sábio, O Herói, O Eterno Jovem, O Trisckster, são papéis assumidos pelas pessoas no curso de suas vidas ou representados por figuras famosas em todas as sociedades, e assim são conhecidas por todos os membros destas. Não é este o caso das recorrências observadas nas visões da ayahuasca. Elas não refletem papéis, funções ou padrões psicológicos gerais, mas são antes conteúdos semânticos específicos - animais, plantas, objetos, paisagens e similares. Conteúdos específicos desse tipo não podem ser reduzidos a um fundo comum da experiência humana e às inquietações (Jung 1976:471; Green 1973:441; Moody 1975:393; Siegel 1980:440) da existência. Portanto, deles não dá conta a moldura conceitual dos arquétipos jungianos ${ }^{11}$.

Até quanto sei, o único estudioso que aborda o tópico das particularidades de conteúdo nas experiências visionárias é Aldous Huxley (1972). Huxley ataca o problema de uma perspectiva, de certo modo, complementar à que foi adotada aqui. Ele não principia pela experiência visionária, mas termina aí. A questão que levanta é: "por que razão seriam as pedras preciosas sempre consideradas como extremamente preciosas?" Eis o tratamento que Huxley dá a essa esplêndida questão:

Resulta algo muito curioso quando pensamos na seguinte questão: por que possível razão os seres humanos empenharam imensas parcelas de tempo, 
energia e dinheiro colecionando pedregulhos coloridos? Não se concebe aí nenhum valor econômico. [...] Plotino, o grante filósofo neoplatônico, [...] afirm[a]: "No mundo inteligível, que é o mundo das idéias platônicas, tudo brilha; conseqüentemente, a mais bela coisa de nosso mundo é o fogo." Essa observação é significativa de vários modos. Antes de mais nada, ela [mostra] que uma grande estrutura metafísica, a estrutura platônica e neoplatônica, foi essencialmente construída sobre uma experiência quase sensória. O mundo das Idéias brilha, é um mundo que pode ser visto; e esse curioso fato, que o mundo ideal pode realmente ser visto, pode ser descoberto em Platão mesmo. No Fedo, Sócrates fala do [...] mundo que ele chama de a outra terra[:] $\mathrm{n}[\mathrm{ele}][\ldots]$ tudo brilha, [...] as próprias pedras no caminho e nas montanhas têm a qualidade das pedras preciosas; e ele termina dizendo que as pedras preciosas de nossa terra, nossas valiosas esmeraldas, rubis, etc. não passam de fragmentos infinitesimais das pedras que se podem ver nessa outra terra; e essa outra terra, onde tudo é mais brilhante e mais claro e mais real do que em nosso mundo, essa outra terra é, diz ele, a visão que têm os afortunados, em sua contemplação. Eis aqui outra indicação de que uma grande idéia metafísica, a Idéia platônica, o sistema platônico do mundo ideal, também está baseado em um mundo da visão. É uma visão dos mais afortunados em sua contemplação, e penso que agora começamos a entender por que as gemas são preciosas: são preciosas por nos recordarem, de alguma forma, algo que já havia em nossos espíritos. Elas nos fazem lembrar desse mundo paradísico, mais-que-real, que por vezes é vislumbrado conscientemente por algumas pessoas e, creio, tenuemente entrevisto pela maioria delas, e de que nós todos, de algum modo obscuro, temos conhecimento em um nível inconsciente. E como disse Plotino, é por causa da existência desse outro mundo, esse outro mundo luminoso, que a coisa mais bonita na terra é o fogo. [...] [Assim,] penso com bastante convicção que a razão por que as pedras preciosas são preciosas é precisamente esta - elas nos recordam esse outro, estranho mundo que há no fundo de nossas mentes, ao qual alguns podem obter acesso e ao qual outros têm acesso espontâneo (Huxley 1956:35-37).

Eu diria que, mutatis mutandis, essa também é a razão pela qual as pessoas têm propensão a criar obras de arte, construir palácios e templos, emocionar-se com música, e a razão pela qual têm afinidade com o transcendente e o religioso (para uma discussão mais extensa, ver Huxley 1956). Eu iria além e proporia que, assim como abelhas são feitas para produzir mel, seres humanos são feitos para construir pirâmides e fazer pinturas. Obviamente, nem todas as pessoas realizam esse potencial, mas no que diz respeito à espécie como um todo, isso é essencial em sua 
natureza. Como a luz interior, as obras de arte são parte essencial dos dons intrínsecos do homo sapiens. No curso da história humana, pessoas fizeram pirâmides e pinturas para dar expressão àquilo que está arraigado em seu ser e conectar-se com isto. É essa também a razão pela qual templos e obras de arte predominam nas visões da ayahuasca.

\section{O universal e o particular}

Neste artigo, destaquei as recorrências transpessoais nas visões da ayahuasca. Isto não implica que não haja variações individuais, idiossincráticas. O exemplo a seguir clarificará o ponto. Certa vez, em uma visão, apareceu-me aquilo que acreditei ser o Templo judaico que havia em Jerusalém até o período romano. Suponho que, se não soubesse do Templo, não teria tido aquela visão. Além disso, não estou afirmando que a imagem que vi era de fato a do templo de Jerusalém, tal como este realmente existiu; certamente, meus conhecimentos, conceitualizações prévias e fantasias acerca do Templo concorreram para essa imagem. Mas o importante aqui é que eu vi um templo. Se o fato de ver o Templo judaico tem a ver com minha história pessoal, a visão de um templo não tem. Palácios e templos, conforme já foi aqui comentado, são dos mais freqüentes elementos de conteúdo nas visões da ayahuasca. Assim, aquilo que aparece nas visões reflete tanto as contingências ligadas à pessoa daquele que a bebe, quanto padrões cuja universalidade transcende a individuação pessoal.

\section{Palavras finais}

As observações e reflexões acima marcam as limitações de várias linhas de teorização em psicologia. As recorrências transpessoais aqui discutidas continuam, em grau considerável, a desafiar o entendimento. Quanto a este caso, as teorias psicológicas não oferecem soluções bem definidas. Mais particularmente, eis alguns problemas que sinto que permanecem: serão as recorrências reflexo de repositórios de informações inconscientes distintos daqueles postulados pela literatura psicológica padrão? Ou eles sugerem, talvez, a existência de outras dimensões da realidade, de tipo platônico, e que não dependem da psicologia pessoal do indivíduo? Esta última possibilidade é, evidentemente, especulativa ao extremo. Se verdadeira, terá ramificações ontológicas e metafísicas 
radicais, e levará a uma Weltanschauung drasticamente distinta do padrão europeu ocidental. De fato, a experiência da ayahuasca levanta sérias questões filosóficas. Entre elas há questões relacionadas às inquietações humanas e à natureza da cultura, à estética, ética, teologia e ao misticismo; muitas trazem enigmas e mesmo mistérios. Todos estes, no entanto, se estendem para além do escopo deste artigo.

Recebido em 15 de abril de 2002

Aprovado em 15 de fevereiro de 2003

Traduzido por Amir Geiger

Benny Shanon é professor de psicologia na Universidade de Jerusalém. É autor de The antipodes of the mind: charting the phenomenology of the ayahuasca experience (2002). 


\section{Notas}

* Grande parte deste artigo foi escrita na condição de bolsista Golestan do Instituto Holandês de Estudos Avançados (NIAS). O auxílio da biblioteca do NIAS na procura de material bibliográfico foi essencial. A pesquisa aqui relatada foi em parte financiada pela Associação Multidisciplinar para Estudos Psicodélicos (MAPS). Este trabalho não se teria completado sem a ajuda de vários assistentes de pesquisa que se envolveram ativamente nos diversos estágios da investigação. Nurit Shacham participou de todo o andamento da pesquisa e da preparação do manuscrito deste artigo. Amit Hagar e Yaron Bromberger tomaram parte na codificação dos dados e seu registro em computador. Yoel Strimling auxiliou nas análises estatísticas. Ele e Yossi Schellas ajudaram na editoração do manuscrito. Sou profundamente grato a todos eles.

1 Alguns leitores talvez sintam que é pouco profissional empregar um termo como bebedor [drinker, no original]. O fato é, no entanto, que ele tem emprego freqüente nos contextos tradicionais de uso da ayahuasca - assim, por exemplo, "El Bebedor de Yagé" (Payaguaje 1983).

2 Harner refere-se a esses itens como "temas". No entanto, na terminologia aqui empregada, são elementos de conteúdo, e não temas.

3 A situação agora parece estar se modificando. Diferentemente de seus predecessores, antropólogos contemporâneos têm de fato experiência direta genuína com a ayahuasca; refiro-me especificamente aos trabalhos de Lagrou (1998), Brissac (1999), Groisman (1999), Sena Araújo (1999) e Labate (2000).

4 Menciono o fato de não ser membro ou afiliado de nenhuma das seitas religiosas que fazem uso da ayahuasca e de que minha pesquisa não teve vínculo oficial algum com elas, nem foi financiada por nenhuma delas. Muitas investigações científicas sobre a ayahuasca não têm esse tipo de autonomia.

5 Além de perguntas sobre os conteúdos de suas visões, os informantes também responderam a questões relativas a efeitos perceptuais não visuais, idéias, reflexões e insights, momentos psicológica e espiritualmente significativos, efeitos e transformações corporais e efeitos ligados à consciência e ao self. Para uma discussão desses tópicos, ver Shanon (2002b).

6 Vários dentre os primeiros relatos também se encontram no volume editado por Luna e White (2000) e publicado quando a presente pesquisa estava a ponto de se completar. Esse volume também traz vários relatos fornecidos por informantes contemporâneos.

7 Esta análise está baseada no estudo cognitivo moderno da categorização, sobretudo o de Rosch e seus colaboradores (1976; 1978). 
8 De um ponto de vista lógico-semântico, essa é uma supercategoria; está incluída aqui devido à escassez, entre os dados, de elementos relativos a ela (voltaremos a isto adiante, no texto).

9 O termo "categoria básica" é tomado de Rosch (1978).

10 Os números de posição dentro dessa reunião de três conjuntos de dados (nos 4, 5 e 6) são as médias dos números de posição obtidos para cada um dos conjuntos, e não os números de posição das médias da freqüência de cada categoria de conteúdo nos três conjuntos.

11 É bastante significativo que - conforme o revela uma pesquisa independente que venho realizando - as visões relatadas por Jung (1976) de fato apresentem elementos comuns de conteúdo específico do mesmo tipo que os encontrados na análise de conteúdo em nível micro aqui exposta. Padrões similares também se encontram em outras experiências psicológicas não-ordinárias, como as experiências místicas, experiências de saída do corpo e de proximidade da morte (ver Green 1973; Moody 1975; Siegel 1980).

\section{Referências bibliográficas}

AMÉRICA INDÍGENA. 1986. Special Volume, 46.

ARÉVALO VALERA, G. 1986. "El Ayahuasca y el curandero Shipibo-Conibo del Ucayali (Perú)". América Indígena, 46:147-161.

BRISSAC, S. 1999. A Estrella do Norte Iluminada Até o Sul: uma etnografia da União do Vegetal em um contexto urbano. Dissertação de mestrado, UFRJ, Rio de Janeiro.

BURROUGHS, W. e GINSBERG, A. 1963. The yagé letters. San Francisco: City Light Books.

CALLAWAY, J., MCKENNA, D., GROB, C., BRITO, G., RAYMON, L., POLAND, R., ANDRADE, E.N., ANDRADE, E.O. e
MASH, D. 1999. "Pharmacokinetics of Hoasca alkaloids in healthy humans". Journal of Ethnopharmacology, 65:243-256.

CENTRO DE MEMÓRIA E DOCUMENTAÇÃO. 1989. União do Vegetal: hoasca-fundamentos e objetivos. Brasília: Centro Espiritual Beneficente União do Vegetal.

CHEN, A. e CHEN, K. 1939. "Harmine: the alkaloid of caapi". Quarterly Journal of Pharmacy and Pharmacology, 12:30-38.

DAVIS, W. 1996. One river: explorations and discoveries in the Amazon rain forest. New York: Simon \& Schuster. DELTGEN, F. 1978/1979. “Culture, drug 
and personality: a preliminary report about the results of a field research among the Yebamasa Indians of rio Piraparana in the Colombian Comisario del Vaupes". Ethnomedizin, 5:57-82.

DER MARDEROSIAN, A., PINKLEY, H. e DOBBINS, M. 1968. "Native use and occurrence of N,N-dimethyltryptamine in the leaves of Banisteriopsis rusbyana". American Journal of Pharmacy, 140:137.

DER MARDEROSIAN, A., KENSINGER, K., CHAO, J. e GOLDSTEIN, F. 1970. "The use and hallucinatory principles of a psychoactive beverage of the Cashinahua tribe". Drug Dependence, 5:7-14.

DOBKIN DE RIOS, M. 1972. Visionary vine: hallucinogenic healing in the peruvian Amazon. San Francisco: Chandler.

.1973. "Curing with ayahuasca in an urban slum". In: M. J. Harner (ed.), Hallucinogens and shamanism. Oxford: Oxford University Press. pp. 67-85.

FISCHER CARDENAS, G. 1923. Estudio sobre el principio activo del yage. Bogota: Universidad Nacional.

FREUD, S. 1953 [1900]. The interpretation of dreams. London: Hogarth Press. Standard Edition, vols. 4 \& 5 .

FURST, P. T. 1976. Hallucinogens and culture. San Francisco: Chandler \& Sharp, Inc. (ed.). 1990 [1972]. Flesh of the gods: the ritual use of hallucinogens. Prospect Heights, IL: Waveland Press.

GOW, P. 1988. "Visual compulsion: design and image in Western Amazonian cultures". Revindi, 2:19-32.

GREEN, C. 1973. Out-of-body experiences. New York: Ballentine.

GROB, C. 1999. "The psychology of ayahuasca". In: R. Metzner (ed.),
Ayahuasca: hallucinogens, consciousness. New York: Thunder's Mouth Press. pp. 214-294.

, MCKENNA, D., Callaway, J., BRITO, G., NEVES, E., OBERLANDER, G., SAIDE, O., LABIGALINI, E., TACLA, C., MIRANDA, C., STRASSMAN, R. e BOONE, K. 1996. "Human psychopharmacology of hoasca, a plant hallucinogen used in ritual context in Brazil". Journal of Nervous and Mental Diseases, 184: 86-94.

GROISMAN, A. 1999. Eu venho da floresta: um estudo sobre o contexto simbólico do uso do Santo Daime. Florianópolis: Editora UFSC.

HALL, C. e VAN DE CASTLE, R. 1966. The content analysis of dreams. New York: Appleton-Century-Crofts.

HARNER, M. J. (ed.). 1973a. Hallucinogens and shamanism. Oxford: Oxford University Press.

. 1973b. "Common themes in South American indian yagé experiences". In: M. J. Harner (ed.), Hallucinogens and shamanism. Oxford: Oxford University Press. pp. 155175.

1973c. "The sound of rushing water". In: M. J. Harner (ed.), Hallucinogens and shamanism. Oxford: Oxford University Press. pp. 15-27. .1980. The way of the shaman. New York: Harper Collins Publishers.

HOLMSTEDT, B. e LINDGREN, J. 1979. "Chemical constituents and pharmacology of South American snuffs". In: D. Efron, B. Holmstedt e N. Kline (eds.), Ethnopharmacologic search for psychoactive drugs. New York: Raven Press. pp. 339-373.

HUXLEY, A. 1956. Heaven and hell. London: Chatto and Windus. . 1972. "Visionary experience". In: J. White (ed.), The highest state of consciousness. New York: Anchor Books. pp. 34-57. 
JUNG, C. G. 1969 [1954]. "Psychological aspects of the mother archetype". In: H. Read, M. Fordham e G. Adler (eds.), The archetypes and the collective unconscious. Princeton: Princeton University Press. pp. 75112.

.1960. The nature of the psyche. Princeton: Princeton University Press.

.1969. The archetypes and the collective unconscious. Princeton: Princeton University Press. . 1976. The visions seminars. Zurich: Spring Publications.

KENSINGER, K. 1973. "Banisteriopsis usage among the Peruvian Cashinahua". In: M. J. Harner (ed.), Hallucinogens and shamanism. Oxford: Oxford University Press. pp. 9-14.

KOCH-GRÜNBERG, T. 1921. Zwei Jahre Bei den Indianern Nordwest-Brasiliens. Stuttgardt: Strecker und Schröder.

KUSEL, H. 1965. "Ayahuasca drinkers among the Chama Indians of Northeast Peru". Psychedelic Review, 6: 58-66.

LABATE, B. C. 2000. A reinvenção do uso da ayahuasca nos centros urbanos. Dissertação de mestrado em Antropologia Social, Unicamp, Campinas, SP.

_ . e ARAÚJO, W. S. (orgs.). 2002. O uso ritual da ayahuasca. Campinas, SP: FAPESP/Editora Mercado de Letras.

LAGROU, E. 1991. Uma etnografia da cultura kaxinawá: entre a cobra e o inca. Dissertação de mestrado, UFSC, Florianópolis.

_.1996. "Xamanismo e representação entre os Kaxinawá". In: E. J. Langdon (ed.), Xamanismo no Brasil: novas perspectivas. Florianópolis: Editora UFSC.

.1998. Cashinahua cosmovision: a perspectival approach to identity and alterity. Doctoral thesis, University of St Andrews.

LAMB, B. 1971. Wizard of the upper Amazon: the story of Manuel Córdoba-Ríos. Boston: Houghton-Mifflin.

LANGDON, E. J. 1979a. "The Siona hallucinogenic ritual: its meaning and power". In: J. Morgan (ed.), Understanding religion and culture: anthropological and theoretical perspectives. Washington, DC: University Press of America.

—.1979b. "Yagé among the Siona: cultural patterns in visions". In: D. Browman e R. Schwarz (eds.), Spirits, shamans and stars. The Hague: Mouton Publishers. pp. 63-82. .1992a. "Dau: shamanic power in Siona religion and medicine". In: E. J. Langdon e G. Baer (eds.), Portals of power: shamanism in South America. Albuquerque: University of New Mexico Press. pp. 41-61. . 1992b. "Yagé and Dau: shamanic power in Siona religion". Shaman's Drum, 29:33-39.

LUNA, L. E. 1986a. Vegetalismo and shamanism among the mestizo population of the Peruvian Amazon. Stockholm: Almqvist \& Wiksell International. . 1986b. "Bibliografía sobre el ayahuasca". América Indígena, 46:235245.

.e AMARINGO, P. 1993. Ayahuasca visions. Berkeley: North Atlantic Books.

LUNA, L.E. e WHITE, S. (eds.). 2000. Ayahuasca reader: encounters with the Amazon's sacred vine. Santa Fe, NM: Synergetic Press.

MABIT, J. 1988. L'hallucination par l'ayahuasca chez les guerisseurs de la Haute-Amazone peruvienne (Tarapoto). Lima: Institut Français d'Etudes Andines. 
MACRAE, E. 1992. Guiado pela lua: xamanismo e uso ritual da ayahuasca no culto do Santo Daime. São Paulo: Editora Brasilense.

MCKENNA, D., CALLAWAY, J. e GROB, C. 1998. "The scientific investigation of ayahuasca: a review of past and current research". The Heffter Review of Psychedelic Research, 1:65-77.

METZNER, R. (ed.). 1999. Ayahuasca: hallucinogens, consciousness, and the spirit of nature. New York: Thunder's Mouth Press.

MOODY, R. 1975. Life after life. Atlanta: Mockingbird Books.

NARANJO, C. 1973a. "Psychological aspects of the yaje experience in an experimental setting". In: M. J. Harner (ed.), Hallucinogens and shamanism. Oxford: Oxford University Press. pp. 176-190.

_ 1973b. The healing journey: new approaches to consciousness. New York: Pantheon Books.

— . 1979. "Psychotropic properties of the Harmala alkaloids". In: D. Efron, B. Holmstedt e N. Kline (eds.), Ethnopharmacologic search for psychoactive drugs. New York: Raven Press. pp. 385-391.

NARBY, J. 1998. The cosmic serpent: DNA and the origins of knowledge. New York: Jeremy P. Tarcher.

OTT, J. 1993. Pharmacotheon: entheogenic drugs, their plant sources and history. Kennewick, WA: Natural Products.

. (1994). Ayahuasca analogues pangean entheogens. Kennewick, WA: Natural Products.

PAYAGUAJE, Fernando. 1983. El bebedor de yaje. Quito: Libri Mundi.

POLARI, A. 1984. O livro das mirações. Rio de Janeiro: Editora Record.

- 1992. O guia da floresta. Rio de Janeiro: Nova Era.
REICHEL-DOLMATOFF, G. 1971. Amazonian cosmos: the sexual and religious symbolism of the Tukano indians. Chicago: The University of Chicago Press.

1975. The shaman and the jaguar: a study of narcotic drugs among the Indians in Colombia. Philadelphia: Temple University Press.

. 1978a. Beyond the milky way: hallucinatory imagery of the Tukano Indians. Los Angeles: UCLA Latin America Center.

. 1978b. Drug induced optical sensations and their relationship to applied art among some Colombian Indians. In: M. Greenhalgh e V. Megaw (eds.), Art in society: studies in style, culture and aesthetics. New York: St. Martin Press. pp. 289-304

(1996). The forest within: the world-view of the Tukano Amazonian Indians. Devon, UK: Themis Books.

. 1997. Chamanes de la selva pluvial. Devon, UK: Themis Books.

REINBURG, P. 1965. Bebidas toxicas de los indios del Amazonas. Lima: Universidad Nacional Mayor de San Marcos.

RIVIER, L., \& LINDGREN, J. E. 1972. "Ayahuasca, the South American hallucinogenic drink: an ethnobotanical and chemical investigation". Economic Botany, 26:101-129.

ROSCH, E. 1978. "Principles of categorization". In: E. Rosch \& B. Lloyd (eds.) Cognition and categorization. Hillsdale, NJ: Lawrence Erlbaum. pp. 28-48.

. MERVIS, C., GRAY, W., JOHNSON, D., \& BOYES-BRAEM, P. 1976. "Basic objects in natural categories". Cognitive Psychology, 7: 573-605.

ROUHIER, A. 1924. "Le yagé: plante télépathique". Paris Médical, 52, 341. 
SCHULTES, R. E. 1972. "An overview of hallucinogens in the western hemisphere". In: P. T. Furst (ed.), Flesh of the gods: the ritual use of hallucinogens. Prospect Heights, IL: Waveland Press. pp. 3-54.

. 1975. "Introduction". In: G. Reichel-Dolmatoff, The shaman and the jaguar: a study of narcotic drugs among the indians in Colombia. Philadelphia: Temple University Press.

. 1982. "The beta-carboline hallucinogens of South America". Journal of Psychoactive Drugs, 14:205220.

. 1986. “El desarrollo histórico de la identificación de las malpigiáceas empleadas como alucinógenos". América Indígena, 46:319-330.

.e HOFMANN, A. 1980. The botany and chemistry of hallucinogens. Springfield, IL: Charles C. Thomas.

. e RAFFAUF, R. 2000. The healing forest: medicinal and toxic plants of the Northwest Amazon. Portland, OR: Dioscoroides Press.

. e WINKELMAN, M. 1995. "The principal American hallucinogenic plants and their bioactive and therapeutic properties". Yearbook of Cross-Cultural Medicine and Psychotherapy, 6:205-239.

SENA ARAÚJO, W. 1999. Navegando sobre as ondas do Daime: história, cosmologia e ritual da Barquinha. Campinas, SP: Editora da Unicamp. SHANON, B. 1997. "Cognitive psychology and the study of ayahuasca". Yearbook of Ethnomedicine and the Study of Consciousness, 6:77-94. .1998a. "Ideas and reflections associated with ayahuasca visions". The MAPS Newsletter, 8:18-21.

_ . 1998b. "Ayahuasca visions: a comparative cognitive investigation".
Yearbook of Ethnomedicine and the Study of Consciousness, 7:227-250. .2001. "Altered temporality". Journal of Consciousness Studies, 8:3558.

2002a. "Ayahuasca and the study of mind". In: B. C. Labate e W. S. Araújo (orgs.), O uso ritual da ayahuasca. Campinas, SP: FAPESP/Editora Mercado de Letras. pp. 631659.

.2002b. "Ayahuasca visualizations: a structural typology". Journal of Consciousness Studies, 9:3-30.

.2002c. The antipodes of the mind: charting the phenomenology of the ayahuasca experience. Oxford: Oxford University Press.

SIEGEL, R. 1980. "The psychology of life after death". American Psychologist, 35:911-931.

SILVA, B. A. da. 1962. A civilização indígena do Vaupés. São Paulo: Linografia Editora.

STRASSMAN, R. J. 2001. DMT the spirit molecule. Rochester, VT: Park Street Press.

TAUSSIG, M. 1987. Shamanism, colonialism, and the wild man: a study in terror and healing. Chicago: The University of Chicago Press.

VILLAVICENCIO, M. 1858. Geographia de la República de Ecuador. New York: Robert Craighead.

WAISBARD, S. R. 1969. Connaissances des Amazonies: chez les chasseurs de têtes d'Amazonie. Paris: Sociéte Continentale d'Editions Modernes Illustrés.

WEISKOPF, J. 1995. "From agony to ecstasy: the transformative spirit of yagé". Shaman's Drum, 39:40-47. 
Resumo

Este artigo examina os conteúdos das alucinações visuais induzidas pela infusão psicotrópica ayahuasca. Ele faz parte de uma investigação fenomenológica mais ampla que busca estudar a ayahuasca de uma perspectiva psicológico-cognitiva. (Até agora, quase todos os estudos da ayahuasca partiram das ciências naturais ou da antropologia.) Análises comparativas quantitativas revelam que certos itens de conteúdo específico são especialmente prevalescentes em visões da ayahuasca e se reencontram em relatos de informantes de diferentes origens socioculturais. Os resultados são discutidos teoricamente à luz de considerações tanto psicológicas como antropológicas.

Palavras-chave Ayahuasca, Cognição, Amazônia, Sonhos, Alucinações
Abstract

This paper examines the contents of the visual hallucinations induced by the Amazonian psychotropic brew ayahuasca. It is part of a comprehensive phenomenological investigation attempting to study ayahuasca from a cognitive-psychological perspective. (So far, practically all studies of ayahuasca pertained either to the natural sciences or to anthropology.) Comparative quantitative analyses reveal that some specific content items are especially prevalent in ayahuasca visions, and that these are encountered in the reports of informants from different personal and socio-cultural backgrounds. Theoretically, the findings are discussed in light of both psychological and anthropological considerations.

Key words Ayahuasca, Cognition, Amazonia, Dreams, Hallucinations 